\title{
DIFERENTES PERSPECTIVAS SOBRE TEORÍA ECONÓMICA
}

\author{
DIFFERENT PERSPECTIVES IN ECONOMIC THEORY
}

\section{Rocío Hartley-Ballestero ${ }^{1}$}

Recibido: $16 / 04 / 2020$

Aprobado: 04/05/2021

\section{RESUMEN}

El artículo es una síntesis de los aportes de algunos pensadores económicos, en relación a cómo estructuraron un modelo macroeconométrico. Este trabajo integra autores que usualmente no son analizados conjuntamente, lo que permite una sintaxis, que facilita la comparación de sus perspectivas sobre teoría económica o reglas de cierre. Es un compendio muy difícil de encontrar, en la abundante literatura especializada, la cual no aborda, además, las especificidades metodológicas de cada autor, en relación a cómo utilizaron las reglas de cierre en sus respectivos modelos. Este vacío es lo que pretende subsanar el documento, utilizando una homogénea estructura matemática, que facilite visualizar y comprender con claridad, cómo cerraron sus correspondientes modelos estos pensadores. Se da cuenta en el análisis de que es posible hacer combinaciones de diversos pensamientos, que conduzcan a un resultado coherente de la realidad que se desea analizar. Posteriormente, se sintetizan las escuelas de pensamiento que los representan.

PALABRAS CLAVE: ESCUELAS DE PENSAMIENTO; MODELOS DE TEORÍA ECONÓMICA; MODELO MARXISTA; MODELO DE KEYNESIANO; MODELO DE SÍNTESIS NEOCLÁSICO; MODELO DE KALECKIANO; MODELO DE KALDOR; MODELO WALRASIANO; MODELO DE JOHANSEN. CLASIFICACIÓN JEL: B13,B14,B22,B23,B21,E1,E12,E21,E22,E24,E25,E37,04,011.

\section{ABSTRACT}

The article is a synthesis of the contributions of some economic thinkers, in relation to how they structured a macroeconometric model. This work integrates authors who are they not usually analyzed together, which allows a syntax, which facilitates the comparison of their perspectives on economic theory or closing rules. It is a very difficult compendium to find in the abundant specialized literature, which also does not address the methodological specificities of each author, in relation to how they used the closure rules in their respective

1 Universidad Nacional de Costa Rica, Escuela de Economía; Código Postal: 86-3000; Heredia, Costa Rica; rocio.hartley.ballestero@una.cr 
models. This void is what the document intends to correct, using a homogeneous mathematical structure, which makes it easier to visualize and understand clearly, how these thinkers closed their corresponding models. He realizes in the analysis, that it is possible to make combinations of various thoughts, which lead to a coherent result of the reality that you want to analyze. Subsequently, the schools of thought that represent them are they synthesized.

KEYWORDS: SCHOOLS OF ECONOMIC THOUGHT; MODELS OF ECONOMIC THEORY; MARXIST MODEL; KEYNESIAN MODEL; NEOCLASSICAL SYNTHESIS MODEL; KALECKIAN MODEL; KALDOR MODEL; WALRASIAN MODEL; JOHANSEN MODEL.

JEL CLASSIFICATION: B13,B14,B22,B23,B21,E1,E12,E21,E22,E24,E25,E37,04,011.

\section{INTRODUCCIÓN}

Los modelos macroeconométricos fueron creados con el objetivo de generar simulaciones de los efectos que diversas alternativas de política económica pueden causar en una economía específica. El uso de estos es hoy una práctica común y una herramienta indispensable para analizar la política económica, incluso para medir el impacto del cambio climático y otros problemas ambientales. Su abordaje implica, irremediablemente, una discusión de fundamentos teóricos metodológicos del pensamiento económico, que permiten la continuación o la innovación de la ciencia económica.

Estos modelos, como cualquier teoría macroeconómica, se formulan en una estructura matemática $y$, por consiguiente, deben cumplir con las condiciones de consistencia (Gujarati \& Porter, 2010), las cuales son: la condición de orden, que establece que el número de ecuaciones del modelo tenga el mismo número de variables endógenas, además, requiere identificar las ecuaciones, elegir cuales variables serán endógenas y cuales exógenas; la condición de rango, la cual implica que aquellas variables escogidas como exogenas de unas ecuaciones y endogenas en otras (ecuaciones simultáneas), deben cumplir con la regla de que sus coeficientes sean diferentes de cero.

El proceso de clasificar endógenas o exógenas las variables como mecanismos de cierre de un modelo y los supuestos que están detrás de su elección, se conocen como reglas de cierre. Idealmente, la teoría de estas reglas refleja adecuadamente la estructura institucional y la conducta de los actores y agentes económicos (Nagatani, 1981). Existen tres formas o tipos de reglas de cierre: anulando una ecuación, agregando una variable endógena y realizando, creando un coeficiente endógeno. Estas reglas serán analizadas en cada modelo desarrollado en el documento.

El artículo provee una síntesis de las diferentes corrientes teóricas, que han dado sustento a la estructuración de un modelo macroeconométrico. Es un aporte complementario de los estudios pioneros de De Haan (1998), Sen (1963) y Taylor y Lysy (1979) que junto con los estudios de Lucas y Sargent (1981), Morishima (1973), Petit Primera (2013) y Solow (1956), que intenta sistematizar las reglas de cierre de algunos de los principales autores económicos, quienes brindan las bases teóricas de los modelos actuales. Este trabajo integra pensadores que usualmente no son analizados conjuntamente, lo que permite una sintaxis histórica de la evolución de los modelos macroeconométricos y facilita la comparación de sus condiciones de cierre. Al utilizar una estructura matemática homogénea para cada modelo por autor, se facilita visualizar, con una mayor claridad, cómo desarrollaron las diferentes perspectivas de cierre cada autor.

El objetivo es brindar un análisis de fácil comprensión y asimilación de las contribuciones de cada autor, que se sintetizan a lo largo del documento. El artículo es un compendio muy difícil de encontrar, en la abundante literatura especializada (Agénor \& Montiel, 2015; De Haan, 1994; Dewatripont \& Michel, 1987; Hosoe et al., 2010; Kaldor, 1980; Lucas, 1983; Modigliani, 1944; Nagatani,1981; O'Ryan et al., 2000; Persson \& Tabellini, 1999; Robinson, 1989; Sargent, 2015; 
Solow, 1957; Sadoulet \& Janvry, 1995, entre otros), en la cual, además, no se aborda específicamente la metodología de cada autor, para establecer sus perspectivas sobre teoría económica, es decir, no explican cómo desarrollaron y utilizaron las reglas de cierre estos autores. En este sentido, existe un vacío por integrar los aportes específicos de cada autor, al abordaje de las diferentes reglas de cierre en sus respectivos modelos, vacío que el artículo trata de subsanar. De esta forma, los modelos que se brindan permiten abordar la discusión sobre cuál debe ser la mejor opción de análisis; un planteamiento clásico, neoclásico, Keynesiano o neokeynesiano, o la combinación de varios pensamientos, para la conformación teórica-metodológica de modelos macroeconométricos y sus posibles cierres.

La macroeconomía, hasta hoy, estuvo bajo al amparo del pensamiento keynesiano y la microeconomía era prácticamente clásica, pero las cosas han cambiado y la macroeconomía moderna integra ambas. El nuevo enfoque desarrolla un conjunto preciso y consistente de principios que explican el comportamiento de la economía actual, como revolución de las expectativas racionales (Lucas \& Sargent, 1981). Considerando estos nuevos principios, el artículo hace una revisión sobre las bases teóricas de autores como Kaldor o Kalecki, que integraron la estructura micro y macroeconómica que creían debe representar una economía. Estos aportes junto con los de otros autores forman los fundamentos de estos nuevos enfoques.

De esta forma, el artículo está dividido en dos grades secciones, en la primera, se brinda una pequeña reseña de los diferentes pensadores teóricos, con sus respetivos modelos, para estructurar política económica. Se parte del análisis de la desagregación de un simple modelo de una economía cerrada, hasta una economía abierta en el corto plazo. En cada modelo se exponen como fue utilizada cada regla de cierre, según la perspectiva de cada corriente de pensamiento, desde la clásica, pasando por los neoclásicos, hasta los estructuralistas o neokeynesianos, es por esta razón que se inicia con el pensamiento de Marx, que se podría calificar como el autor más puramente clásico de tal exposición. En una segunda parte, se sistematizan las escuelas de pensamiento que nacieron a la luz de los aportes de estos autores y que son las escuelas que hoy crean y recrean constantemente los modelos de la ciencia económica. Finalmente, se presentan las reflexiones que, se abstraen de este recorrido de las perspectivas sobre teoría económica de cada autor y sus corrientes de pensamiento.

\section{RESEÑA DE LOS DIFERENTES PENSADORES TEÓRICOS}

\section{UN MODELO DE ECONOMÍA CERRADA}

Es un modelo macroeconómico que explica, de forma simple, como funciona una economía sin comercio exterior. Describe cómo se determinan los precios en diferentes mercados, debido al comportamiento de la oferta y la demanda de bienes y servicios; $y$ de los recursos productivos; $y$ cómo de esta relación se obtiene la renta de las empresas y de las familias. En una economía cerrada, al no existir relación con otros países, se cumplen las siguientes condiciones:

Producto interno bruto = consumo privado + inversión interna + gasto público

Inversión nacional = ingreso nacional - ahorro privado + utilidades de las empresas

La primera fórmula muestra que el consumo de los agentes privados y públicos, así como los recursos destinados a inversión, provienen de la producción interna.

La segunda determina que la inversión es financiada con recursos internos, tanto públicos, como privados. 
El modelo considera primero la más simple estructura con únicamente oferta y demanda agregada, después se desagregará la demanda y finalmente también la producción.

\section{Demanda Agregada y Producción}

La más simple representación de un modelo-macro es, por ejemplo, el siguiente:

$$
\begin{aligned}
& X_{s}=\bar{X}_{s} \\
& X_{d}=\bar{X}_{d} \\
& X_{s}=X_{d}
\end{aligned}
$$

Este modelo permite el análisis de la demanda y la oferta en términos agregados, lo cual proporciona una claridad de como el dinero, el consumo, la inversión, los impuestos y el gasto público, convergen en la actividad económica de un país, con una economía cerrada, afectando la producción, el ahorro y los precios.

La producción total real $\mathrm{u}$ oferta real, $X_{s}$, es fijada por un monto dado de producción $\left(\bar{X}_{s}\right) y$ la demanda total real $X_{d}$ es fijada por un cantidad dada de consumo $\left(\bar{X}_{d}\right)$. El modelo contiene tres ecuaciones y únicamente dos variables y está sobre determinado. Únicamente por accidente una solución sería obtenida. El primer camino de cierre de este modelo es eliminando una ecuación. Una posibilidad es eliminando la primera y tener así una producción determinada por demanda, propuesta común keynesiana.

Alternativamente, la ecuación eliminada podría ser la demanda, si está determinada por la oferta, un supuesto usual aplicado en la tradición neoclásica ¿Qué regla de cierre es la adecuada? Depende principalmente del grado en que la capacidad de producción es subutilizada.

El segundo camino es agregar una variable endógena. Puesto que en una economía cerrada se tiene que asumir, que una diferencia entre demanda $y$ oferta no puede ser eliminada por el comercio exterior. En cambio, se podría tomar el cambio en los inventarios como una variable de ajuste. Si la demanda excede a la oferta seria satisfecha por un decrecimiento en los inventarios, que es únicamente factible si el stock es lo suficientemente grande. En cambio, si la oferta excede a la demanda, los inventarios incrementarían (De Haan, 1998; Lucas, 1983; Lucas \& Sargent, 1981; Solow, 1956, 1957).

Otra variable endógena, que puede ser agregada, es el nivel de precios (p). Si ambas, demanda y oferta, son determinadas en función del nivel de precios, se tendrá un modelo consistente con tres variables endógenas y el mismo número de ecuaciones, y se cumple que los coeficientes de las variables endógenas del sistema, en términos absolutos, son diferentes de cero (Sadoulet \& Janvry, 1995).

\section{Desagregación de la demanda}

Uno de los objetivos fundamentales de la macroeconomía es explicar por qué fluctúa la producción, sabiendo que el crecimiento económico es muy irregular. De esta forma, es importante estudiar los determinantes de la demanda agregada y en particular el comportamiento del consumo y la inversión, para observar fácilmente la relación de ambas con el ingreso. Las variaciones de la demanda agregada son en parte resultado de los cambios de la política fiscal y monetaria; $y$ de las decisiones individuales sobre el consumo y la inversión, fluctuaciones que alteran la producción al corto plazo y los precios al largo. 
La importancia de este modelo Keynesiano es la interdependencia de la producción y el gasto. Este último determina la producción y el ingreso, pero a su vez, la producción y el ingreso fijan el gasto. Para comprender, por ejemplo, cómo afecta el gasto público o el cambio tecnológico a la producción agregada, es indispensable desagregar la demanda en las variables que la determinan.

Se desagrega la demanda en consumo (c) e inversión (i) y se agregan ecuación explicativa para ambas variables. El consumo es relacionado al ingreso, por medio de la propensión marginal a consumir $(\gamma)$ y la inversión es una proporción fija $(\iota)$ del stock dado de capital $(\bar{k})$ y la producción es igual a la oferta real $(Y)$.

Analizar la inversión es substancial porque, es el gasto dedicado a incrementar o a mantener el stock de capital, de lo cual se desprende también, que es un concepto fundamental para entender la oferta agregada. La demanda de inversión es un factor, que explica los índices del nivel de vida en el largo plazo. Además, "la inversión es un componente de la demanda extremadamente volátil, de modo que entender cómo se comporta es esencial para explicar las fluctuaciones económicas en el corto plazo" (Romer, 2006, p. 392).

$$
\begin{aligned}
& X_{s}=\bar{X}_{s} \\
& Y=X_{s} \\
& c=\gamma Y \\
& i=\imath \bar{k} \\
& X_{d}=c+i \\
& X_{s}=X_{d}
\end{aligned}
$$

Hay cinco variables endógenas: $X_{s}, Y, X_{d}, c$ y $i$, pero seis ecuaciones, así que para poder resolver el modelo, se puede hacer uso de un procedimiento usual en el pensamiento neoclásico (Bridel, 1997), que consiste en eliminar la ecuación de inversión, esta sería ahora definida como el balance después de satisfecho el consumo.

Otra posibilidad de cierre la ofrece Johansen (1960), quien introduce un impuesto al consumo, así reduce el consumo, para generar el suficiente ahorro para financiar la inversión fijada. También, se puede introducir una variable precio ( $p$ ) y fijar una variable en términos nominales. La inversión sería la variable apropiada a fijar, así la ecuación de la inversión se replantea de esta forma:

$$
i=\bar{I} / p
$$

Haciendo que el nivel de precios actúe como la variable de equilibrio (De Haan, 1998). Además, se podrían convertir los coeficientes $\gamma$ o $\iota$, en variables endógenas. El dejar la inversión como una variable ajustable implica un simple cierre neoclásico. Por otra parte, si se endogeniza la propensión marginal a consumir, se requiere una especificación del mecanismo que lo ajusta, como más adelante se demostrará en el modelo de Walras.

Alternativamente, se podría ajustar el consumo, pero esto requiere un cambio en la distribución y composición del ingreso, lo que se desarrolla a continuación. 


\section{Desagregación de la producción y de la demanda}

La desagregación se realiza con el modelo de la síntesis neoclásica-keynesiana, qua presenta una función de producción y demanda neoclásica, y una oferta de trabajo keynesiana, como se muestra en el siguiente modelo. Posteriormente, se explicará con mayor detalle en qué consiste la síntesis neoclásica. Esta es la base matemática de los modelos que se analizarán en la siguiente sección, en especial los Keynesianos.

La síntesis neoclásica estructuró un modelo de equilibrio general agregado, que supone flexibilidad en los precios y que es posible obtener un equilibrio en los diferentes mercados en pleno empleo, así como, también en situaciones de desequilibrio. Hicks (1989) propuso la síntesis, difundida después en el modelo IS-LM, para determinar el nivel de producción y empleo.

"El modelo demuestra que el producto está determinado por la oferta y la demanda, y las situaciones que afecten a la demanda, afectaran el nivel de empleo en el corto plazo," (Jiménez, 2011, p. 562), como se muestra en la ecuación 1, que representa la producción de pleno empleo $(f(\bar{l}, \bar{k}))$. La desagregación de la producción y la demanda de esta forma permiten demostrar cómo influyen las variables nominales en las reales en el corto y largo plazo. El modelo evidencia que, con políticas propicias, tanto, fiscales como monetarias, el Estado podría frenar un posible desempleo o una alta inflación, amortiguando las fluctuaciones de los ciclos económicos.

Con la integración de los planteamientos clásicos y keynesianos, el ingreso total puede ser desagregado en salarios (Yl) y en ganancias (Yk). La producción está en función de un stock de capital dado $(\bar{k})$ y una oferta de trabajo dada $(\bar{l})$. Se agrega, además, una tasa de salario real $(\omega)$ y una tasa de ganancia $(\rho)$, las cuales se igualan a sus productividades marginales, se asumen diferentes propensiones para el consumo del capital $(\gamma k)$ y del trabajo $(\gamma l)$. Otro supuesto es que el tipo de mercado es de competencia perfecta. Con estos cambios, se obtiene el siguiente modelo según De Haan (1998):

$$
\begin{aligned}
& X_{s}=f(\bar{l}, \bar{k}) \\
& \omega=\partial X_{s} / \partial 1 \\
& \rho=\partial X_{s} / \partial \mathrm{k} \\
& y 1=\omega \bar{l} \\
& y_{k}=X_{s}-y_{1} \\
& c=\gamma 1 y_{1}+\gamma k y_{k} \\
& i=\iota \bar{k} \\
& X_{d}=c+i \\
& X_{s}=X_{d}
\end{aligned}
$$

Con este modelo es posible ajustar el consumo ante cambios en la distribución del ingreso, entre trabajo y capital, considerando que la inversión es fija. Esto es el cierre de Kaldor (1980). Si la ecuación que determina el salario es eliminada, $\omega$ sería la variable que se ajustaría para generar el equilibrio, se convierte en una variable exógena. Si la demanda excede a la oferta, o equivalentemente, la inversión excede al ahorro, $\omega$ decrece y el ingreso del capital o ganancia 
aumenta, para restablecer el balance macro. Esta regla de cierre es del tipo 3, puesto que $\omega$ puede ser definida como ( $w / p)$. Si se fija el salario nominal $(w)$ exógenamente, el nivel de precios seria la variable que ajustaría el equilibrio (Sadoulet \& Janvry, 1995).

Keynes ofrece otra posibilidad de cierre (Taylor \& Lysy, 1979), la cual consiste en agregar una variable endógena, o mejor una variable exógenamente fijada es convertida en una variable endógena, es decir el empleo (1). El nivel de empleo y también el ingreso, según la función de producción, serían las variables ajustables.

\section{ALTERNATIVAS TEÓRICAS DE UN MODELO DE ECONOMÍA CERRADA}

\section{Modelo clásico de Marx}

Los modelos tanto de economía cerrada como abierta de Marx están basados en los esquemas de reproducción que el autor analiza en el Tomo II de El Capital (Marx, 1980), con los esquemas, se analiza la reproducción social del sistema capitalista y, como dice Morishima (1973), es un modelo de equilibrio general, que tiene dos componentes principales: la teoría del valor y la teoría de la reproducción.

El primer componente sería analizado en este modelo cerrado, que presenta las siguientes características fundamentales: fija la tasa de salario real y la producción a la oferta, como se muestra en el modelo siguiente. El salario es determinado por factores institucionales y de esta forma en el corto plazo, es una variable exógena (ecuación 20). Obsérvese, que este modelo utiliza a la demanda como exógena. Para los clásicos, la demanda está determinada, por condiciones que no están relacionas con la utilidad marginal. A Marx le interesa la producción, no la compra de bienes, por eso, para este autor, la demanda es un dato. Él explica que:

Si la demanda permanece invariable, las mercancías se venderán por su valor comercial. El cambio o venta de las mercancías por su valor es lo racional, la ley natural que rige su equilibrio; de ella debe partirse para explicar las divergencias; $y$ no al revés, partiendo de las divergencias para explicar la ley (Marx, 1980, Tomo III, p. 237).

Además, no existe una ecuación de igualdad entre la oferta y demanda, porque como explica Marx:

Cuando la demanda y la oferta coinciden, dejan de actuar; por ello precisamente se venden las mercancías por su valor comercial. Cuando dos fuerzas iguales actúan en sentido contrario se neutralizan, no se manifiestan al exterior; por lo tanto, los fenómenos que se produzcan en estas condiciones deberán explicarse por causas ajenas a la intervención de estas dos fuerzas (1980, Tomo III, p. 239).

La estructura del modelo es la siguiente según De Haan (1998):

$$
\begin{aligned}
\omega & =\bar{\omega} \\
1 & =f(\omega) \leq \bar{l} \\
X_{s} & =f(1, \bar{k}) \\
y 1 & =\omega l
\end{aligned}
$$




$$
\begin{aligned}
y_{\mathrm{k}} & =x_{s}-y_{1} \\
\rho v & =y_{\mathrm{k}} / y_{1} \\
c & =y_{1}+\gamma \mathrm{k} y_{\mathrm{k}} \\
i & =x_{d}-c
\end{aligned}
$$

Establece que, en cualquier punto del tiempo, la tasa de salario real puede desviarse del fijado institucionalmente o del salario real convencional. Si el actual excede al convencional, por ejemplo, por una escasez temporal de trabajo, la tasa de ganancia declina, provocando que tanto la inversión, como el crecimiento disminuyan (Marx, 1980, Tomo III). Tal resultado implica que, un cambio en la proporción ganancia - salario induciría a los empresarios a sustituir trabajo por capital (ecuación 24). Esto reduciría la demanda de trabajo futura y así el salario real retornaría a sus niveles convencionales, es decir bajos. El proceso de producción capitalista es a la vez un proceso laboral, de formación de valor y un proceso de valorización (plusvalía). Cualquier elemento que estimule una reducción del salario real, aumentaría la tasa de plusvalía $(\rho v)$, recuérdese que esta tasa, calcula el grado de explotación del trabajador, como la razón entre la ganancia del capitalista, que es la plusvalía y el capital variable, que son los salarios. Lo que establece que:

El desarrollo del capital y el proceso tecnológico y la mecanización generan un excedente de trabajo no utilizado total o parcialmente, que sirve de reserva de trabajo potencialmente utilizable, que varía según las condiciones y la fase del ciclo económico y que sobre todo actúa como poderoso regulador del salario (manteniéndolo en niveles bajos) (Erice Sebares, 2013, p. 31).

En los modelos clásicos, el crecimiento de la población es a veces relacionado con la tasa de salario real y Marx mantiene este supuesto. Cambios en el crecimiento de la población conducirían a la tasa de salario a ser fijada a un mínimo social (De Haan, 1998). El objetivo del modelo es mostrar, precisamente, como se desenvuelven los salarios que, a criterio de Marx, están estipulados por razones sociales e históricas; lo que implica que la plusvalía es una afirmación de la explotación del trabajador (Marx, 1980, Tomo I).

Otra característica importante del modelo es que solamente se asume una propensión a consumir, debido a que solo el capitalista ahorra (ecuación 25), el trabajador consume todo su ingreso, por eso, la ecuación de consumo cambia en relación con el modelo anterior, como se muestra en la ecuación 25. Considera, además, que el precio es establecido por la competencia entre los empresarios. Para Marx, en el capitalismo, las fluctuaciones de los precios se deben a los costos de producción y la cuota media de ganancia (Marx, 1980, Tomo III).

El modelo marxista desarrolla las contradicciones $y$ asimetrías que caracterizan al capitalismo, mostrando la propensión de este sistema al desequilibrio, debido al persistente desajuste entre la oferta (producción) y la demanda (consumo) de mercancías, que provoca una crisis de sobreproducción, al generar una acumulación de mercancías que impide la realización de su valor y estimula la caída de los precios de mercado y de la tasa de ganancia (Marx, 1980, Tomo III). Esto causa una contracción de la inversión y por consiguiente la demanda agregada, situación que se muestra en la última ecuación, la cual cierra el modelo y utiliza la segunda regla de cierre, creando una variable endógena la inversión (i).

La inversión, acumulación de capital en términos de Marx, es por tanto fundamental: se produce cuando las ganancias se consagran a adquirir capital constante (bienes de 
capital) o capital variable (salarios), para hacer crecer la producción. La acumulación se determina por la proporción de plusvalía en relación con el gasto en capital, de forma que se infiere un indicador esencial de la tasa de ganancia, con relación igualmente directa con el volumen total de la misma (Manera \& Molina, 2018).

El modelo determina una tecnología, representada por medio de la relación entre el capital constante $(\bar{k})$ y el capital variable (I), esta se denomina composición orgánica del capital (COC) (ecuación 22). La composición orgánica puede cambiar aun cuando las relaciones reales entre capital $y$ trabajo no cambien, por ejemplo: si la distribución del ingreso, entre el del trabajador y el ingreso de la plusvalía, cambian, debido a variaciones en los precios relativos de los factores de producción, se altera la COC, situación representada en las ecuaciones 23, 24 y 25.

Dependiendo de lo que suceda con los componentes de la COC, la tasa de ganancia tendrá o no una tendencia decreciente. Recuérdese que la tasa es una relación entre plusvalía y la cantidad de capital (constante y variable) desembolsado. De acuerdo con el análisis de Marx (Marx, 1980, Tomo III; ver también: Mandel, 1974; Morishima, 1973; Schumpeter, 1983), la cuota de plusvalía tiende a aumentar con el paso del tiempo, debido a diversos factores entre los que se destaca: el aumento en el grado de explotación, el incremento en la jornada de trabajo, el crecimiento en la intensidad de trabajo, el descenso del salario, o el incremento del ejercito industrial de reserva que presiona a la caída del salario. Todas estas situaciones contrarrestan a la caída de la tasa de ganancia.

Además, la COC tiende a aumentar con la innovación y la introducción de nuevas tecnologías. Por ende, la tendencia final de la tasa de ganancia, dependerá de cuál de los dos factores se imponga en el largo plazo. Los factores que influyen en la cuota de plusvalía tienen ciertos límites, ya que el grado de explotación en algún momento alcanza su máximo, así como la duración de la jornada de trabajo o la intensidad del trabajo, asimismo, el salario no puede ser menor al de subsistencia, entre otros; en tanto que el cambio tecnológico no presenta límites estructurales, por lo que la composición orgánica del capital se incrementará incesantemente a lo largo del tiempo. Como resultado Marx, (1980, Tomo III), llega a la conclusión de que existe una ley de tendencia decreciente de la tasa de ganancia, que se verifica en el largo plazo y que es la ley más importante del sistema capitalista.

\section{El modelo de Walras}

La aportación de este autor al análisis económico, consiste en la introducción de lo que él define como el objetivo de estudio de la economía política pura. Este consiste en una formalización completa de la interacción de los agentes económicos a través de los mercados, situación que permite explicar la distribución de los recursos y la deducción de los precios. (De la Garza, 1998). Es el primer modelo de equilibrio general.

En este modelo los agentes económicos toman decisiones considerando, solamente, el sistema de precios y sus propios intereses, esto provoca que la oferta $y$ la demanda se enfrenten, $y$ sean determinadas en cada mercado; $y$ que cada mercado puede estar en equilibrio o en desequilibrio (De la Garza, 1998).

El modelo asume competencia perfecta y la producción es determinada por la oferta, supuesto que el modelo de la síntesis neoclásica retoma. La demanda es exógena, es igual a los precios, de esta forma, se puede identificar el consumo intermedio de los múltiples sectores de producción.

Mantiene tanto la ganancia, como el nivel de salario iguales a sus productos marginales, utiliza la tasa real de salario ( $\omega)$, y asume que tanto el capital, como el trabajo tienen una propensión de consumo, también agrega una ecuación de la tasa de ganancia del capital ( $\rho)$, pero con la diferencia de Marx, que la oferta de trabajo no está dada. La estructura sería según De Haan (1998): 


$$
\begin{aligned}
x_{s} & =f(1, \bar{k}) \\
\omega & =\partial X_{s} / \partial 1 \\
\rho & =\partial X_{s} / \partial \mathrm{k} \\
y 1 & =\omega \bar{l} \\
y \mathrm{k} & =\rho \overline{\mathrm{k}} \\
\gamma & =f(\omega / \rho) \\
c & =\gamma\left(y_{1}+y_{\mathrm{k}}\right) \\
i & =X_{d}-c
\end{aligned}
$$

Adicionalmente, Walras (2014) iguala los gastos de los trabajadores y de capital, con sus ingresos. Esto significa que el valor de sus ofertas es igual al valor de sus demandas (ecuaciones 31 y 32), las cuales representan la llamada Ley de Walras (Morishima, 1973).

Walras cierra el modelo creando un coeficiente endógeno, el cual es la propensión a consumir $(\gamma)$, aplicando la tercera regla de cierre de un modelo (Walras, 2014). Ahora la propensión marginal a consumir (PMC), está definida como una función determinada por la proporción de cambio del salario, ante un cambio de la ganancia (Morishima, 1973), como se muestra en la ecuación 33. Cada vez que la ganancia aumente, el salario disminuye y la función del coeficiente de la PMC del trabajador disminuye (ecuación 34) y con él, el consumo. Sin embargo, estos efectos también provocan un aumento del ahorro del capital y en consecuencia de la inversión; lo cual representa un mecanismo que logra mantener el pleno empleo y el equilibrio en el modelo. De esta forma, para poder aumentar la ocupación, debe suceder un descenso en la tasa del salario real (Walras, 2014).

Obsérvese que, con este mecanismo, como señala Morishima, "los modelos de Marx son muy similares al de Walras, el esquema de Marx de reproducción simple corresponde al sistema de producción de equilibrio general estático de Walras" (1973, p.105). Sin embargo, a pesar de que compartía el interés en una reforma social, como Marx, creía en un régimen de libre competencia, que condujera a una justicia social y, por tal razón, asienta las bases para desarrollar un análisis de la economía muy aleado del valor-trabajo y más sustentado en la escasez, principios de los neoclásicos.

Aunado a esto, Walras utiliza, también, otro mecanismo de cierre: asume que la inversión y el ahorro, en conjunto, pueden conducir a un equilibrio de pleno empleo, al asumir que todo lo que se ahorra es invertido. Esta condición se logra manteniendo variable la tasa de interés. El mecanismo mencionado no aparece explícitamente en el modelo, pero se evidencia en su funcionamiento (Morishima, 1977) en las ecuaciones 34 y 35. Si existiera un exceso de inversión, se aplicaría una tasa de interés mayor, para contrarrestar el aumento de la inversión. Como el mercado se encuentra en pleno empleo, el equilibrio se logra con la distribución de una única cantidad de bienes (y por tanto de trabajo) entre consumo e inversión (Sadoulet \& Janvry, 1995), a través de la fluctuación de la tasa de interés que media entre el ajuste de ahorro e inversión. Por tanto, el consumo está determinado por esta última, según Walras (2014). Esto es factible, porque no existe atesoramiento y por tanto tampoco especulación. El capital es definido como un bien y no como una suma de dinero.

De esta forma, si por ejemplo, se introduce un impuesto al modelo, no afectaría el nivel de producción al encontrarse la economía en pleno empleo, solo se provocaría un cambio en la proporción de ahorro y consumo. El capitalista, por un lado, disminuye su consumo, por la 
aplicación del impuesto y dado que sus ahorros son la diferencia entre el nivel de producción $y$ consumo, $y$ como este modelo no contempla el Estado $y$ es cerrado, se asume que conforme disminuye el consumo aumenta la inversión, porque el ahorro aumenta, dado que la inversión es igual al ahorro por encontrarse en pleno empleo, solo se verían afectados los salarios reales y la tasa de interés aumentaría para lograr de nuevo el equilibrio (Morishima, 1977).

\section{Modelo neoclásico de Keynes}

El modelo permite determinar un nivel de equilibrio con cambios relativos en la producción $y$ en los ingresos agregados, analizando las frecuentes perturbaciones de los mercados de bienes y servicios. Keynes, de esta forma, estructura un modelo del crecimiento económico usando una función de oferta y demanda agregada, enfocándose en las variables de consumo e inversión (Taylor \& Lysy, 1979). Es un primer intento, con el cual posteriormente desarrolla su teoría general, que continua con algunos postulados neoclásicos y de otros se separa completamente, como se observara en su modelo de la teoría general. El presente modelo es una forma simple de mostrar cómo funcionan sus postulados, como una introducción, que permita entender su mayor aporte a la economía su modelo de la Teoría General, con el cual se crea la macroeconomía.

Diferencia el crecimiento económico potencial y el gasto planificado del real. El análisis se centra en el comportamiento del ingreso y del gasto del gobierno (g) (ecuaciones 39, 40 y 43). Utiliza una función de oferta con sus componentes fijos (ecuación 36), una ecuación que posteriormente será la carta de presentación de la síntesis neoclásica. Moldea a un país desarrollado y rico, con tendencia a que el ahorro excede la demanda de inversión (ecuaciones 40 y 42), es decir, la economía se podría estancar por los bajos niveles de inversión. Este modelo sería según De Haan (1998):

$$
\begin{aligned}
& X_{s}=f(\bar{l}, \bar{k}) \\
& \omega=\partial X_{s} / \partial l \\
& \rho=\partial X_{s} / \partial k \\
& y l=\omega l \\
& y k=\rho \bar{k} \\
& c=\gamma l y l+\gamma k y_{k} \\
& i \quad=i \bar{k} \\
& g \quad=X_{d}-(c+i)
\end{aligned}
$$

La producción está determinada por la demanda (variable exógena) y el pleno empleo puede ser alcanzado, al mantener la demanda al nivel de la producción (Sen, 1963). Una caída en la demanda puede ser prevenida por medio del gasto público, ya sea como inversión o como consumo (última ecuación). Aumentar la demanda efectiva al nivel de pleno empleo, puede ser realizado por aumentos del consumo privado, vía una reducción de impuestos o por incrementos en el gasto público (Persson \& Tabellini, 1999). Por otra parte, también se vería afectada por cambios en el ahorro público, por ejemplo, si este sufre una disminución, puede ser compensado con emisiones de bonos públicos, para absorber el exceso de ahorro o por emisión monetaria. El gasto público (g) sería 
la variable clave para generar el equilibrio. Con la incorporación del Estado, no se trata de restringir la función de inversión, sino identificar el impacto que el Estado ejerce sobre la inversión, para alcanzar el crecimiento de la economía.

Los precios, y especialmente los salarios (rigidez de los precios), responden lentamente a las variaciones de la oferta y la demanda, algo que genera situaciones periódicas de escasez y excedentes, sobre todo de mano de obra. Las variaciones de la demanda agregada, ya sea previstas o no, tienen su mayor impacto a corto plazo en el producto real y en el empleo, no en los precios (Jahan et al., 2014, pp. 53-54).

Keynes postula que, al ser los precios un tanto rígidos, los cambios de cualquier variable del gasto (consumo, inversión o gasto público) provocan que cambie el nivel de producción; el modelo se podría cerrar, eliminando la primera ecuación e igualando la producción a la demanda o, como lo muestra el modelo, generando una variable endógena de consumo (ecuación 41).

\section{Modelo de la Teoría General de Keynes}

Con este modelo, Keynes (1936), demuestra que es el nivel de la demanda agregada el que determina el nivel de empleo y no el precio del trabajo como en la economía clásica (ecuación de precios $(p)$ y del salario real $(\omega)$ ). De esta forma, niega que el pleno empleo se obtenga de los mercados competitivos en equilibrio (Keynes, 1936). Introduce, además, el concepto de demanda efectiva (punto de intercepción entre oferta y demanda agregada) representado en la última ecuación, la cual es la columna vertebral de la Teoría General.

"El modelo desarrolla al sistema capitalista en un ambiente económico volátil y en el cual el pleno empleo es solamente un caso particular". (Dillard, 1981, p. 5). Con él Keynes demuestra, que puede existir desempleo en condiciones de competencia perfecta. Por otra parte, el nivel de ingreso jugaría el rol de ajuste del modelo (Keynes, 1936), por el multiplicador del gasto y como resultado de que el nivel de producción sea determinado por la demanda. La estructura del modelo es sugerida por De Haan (1998):

$$
\begin{aligned}
& \omega=\omega / p \\
& p=f\left[\left(X_{d}-X_{s}\right)\right] \\
& 1=f(\omega) \leq \bar{l} \\
& {\left[\omega=\partial X_{s} / \partial I\right]} \\
& X_{s}=f(\bar{l}, \bar{k}) \\
& y 1=\omega l \\
& \rho=\partial X_{s} / \partial \mathrm{k} \\
& y \mathrm{k}=\rho \bar{k} \\
& c=\gamma l y 1+\gamma \mathrm{k} Y \mathrm{k}
\end{aligned}
$$




$$
\begin{aligned}
i & =\imath \bar{k} \\
X_{d} & =c+i \\
X_{s} & =X_{d}
\end{aligned}
$$

Se alcanza el equilibrio cuando la producción iguala a la demanda y el ahorro alcance a la inversión (ecuación 55 y 53).

Keynes utiliza la segunda regla de cierre, al agrega al modelo una variable endógena, la cual es el empleo (1), En comparación al modelo de Walras, se diferencia principalmente, por que la demanda de trabajo estaría ahora determinada tanto por el salario real, como por su productividad marginal, al no existir pleno empleo (Taylor \& Lysy, 1979). El salario real será el salario nominal (w) entre el nivel de precios y los precios están en función de la diferencia entre demanda y oferta. Por tanto, el salario también variaría en respuesta a esta diferencia (ecuaciones 45 (p) y $44(\omega)$ ). En caso de exceso de demanda el precio se elevaría y la tasa de salario decaería. La caída tiende a moderar el impacto sobre la demanda de consumo (Sadoulet \& Janvry, 1995). Si la inversión aumenta se producirá un exceso de demanda, por la magnitud en que aumentado la inversión, lo que equivale a un exceso de inversión. Siguiendo la argumentación Keynesiana (Taylor \& Lysy, 1979), las empresas deben variar sus planes de producción para maximizar sus ganancias, elaborando más producto, lo que genera más ingreso, el ingreso resultante provocará un aumento del consumo.

Esto dará lugar a un nuevo aumento del ingreso, que provoca un aumento en el ahorro. Asimismo, el multiplicador del gasto estima en qué medida la demanda puede crear oferta e ingreso adicional; "cualquier esfuerzo por consumir una parte de los ingresos incrementados, estimulará la producción hasta que el nuevo nivel (y distribución) de los ingresos proporcione un margen de ahorro lo suficiente para que compense el exceso de inversión” (Keynes, 1936, p. 110). Para la teoría keynesiana:

El empleo total depende de la demanda total y el paro es el resultado de una falta de demanda total. La demanda efectiva se manifiesta en el gasto de la renta. Cuando el empleo aumenta, aumenta la renta. Es un principio fundamental el de que cuando la renta de una comunidad aumenta, también aumentará su consumo, pero el consumo menos que la renta. Por lo tanto, para que haya una demanda suficiente para mantener el nivel de empleo, tiene que haber un nivel de inversión real equivalente a la diferencia entre la renta y el consumo, el empleo no puede aumentar a no ser que aumente la inversión (Dillard, 1981, p. 31).

Por ello, la rigidez de los salarios no es el único factor del desempleo, hay otras causas: las decisiones de inversión, el nivel de oferta total y la propensión del consumo. Keynes resalta el hecho de que, tanto el desempleo, como la inflación dependen de la demanda efectiva; si esta es insuficiente produce desempleo, si sucede lo contrario hay inflación (Dillard, 1981).

Acepta la conclusión clásica que, aumentos en la cantidad de dinero, incrementa el nivel de precios, pero como un agregado del efecto que ejerce sobre los salarios y la ocupación. Las variaciones del dinero no afectarán los precios mientras exista algún tipo desocupación, lo que significa que, conforme aumenta la ocupación subirán (precios) exactamente en proporción al aumento de la demanda efectiva, provocado por un aumento de la cantidad de dinero. Otro factor de aumento de los precios es el alza del costo de la mano de obra (Keynes, 1936). 
Con el modelo, Keynes expone los principales factores que provocan el ciclo económico: las fluctuaciones de la eficiencia marginal del capital (Keynes, 1936), las variaciones en la propensión marginal a consumir y la preferencia por la liquidez.

\section{Modelo de síntesis neoclásico de Johansen}

El modelo permite determinar un nivel de equilibrio con cambios relativos en la producción $y$ en los ingresos agregados, analizando las frecuentes perturbaciones de los mercados de bienes y servicios. Keynes, de esta forma, estructura un modelo del crecimiento económico usando una función de oferta y demanda agregada, enfocándose en las variables de consumo e inversión (Taylor \& Lysy, 1979). Es un primer intento, con el cual posteriormente desarrolla su teoría general, que continua con algunos postulados neoclásicos y de otros se separa completamente, como se observara en su modelo de la teoría general. El presente modelo es una forma simple de mostrar cómo funcionan sus postulados, como una introducción, que permita entender su mayor aporte a la economía su modelo de la Teoría General, con el cual se crea la macroeconomía.

Es un modelo de crecimiento de síntesis neoclásico desagregado, construido con base en un marco de insumo-producto de la economía, introduce "ecuaciones de comportamiento para consumidores $y$ productores, asumiendo pleno empleo de recursos y encontrando el equilibrio económico a través de ecuaciones de balance macroeconómico, sin la necesidad de que la economía se encuentre en un equilibrio óptimo" (Escobar-Espinoza et al., 2017, p. 538); permite la sustitución entre trabajo y capital, los precios relativos son endógenos e influyen sobre el desarrollo de la demanda de consumo.

El pleno empleo lo asegura mediante la ausencia de un mecanismo que integre el ingreso total y la demanda total, utiliza un ajuste automático sobre la demanda total de consumo privado, que se acopla exactamente en el nivel que permite crear una demanda suficiente de pleno empleo. El supuesto subyacente es que, en la política económica a corto plazo, siempre se cuenta con instrumentos monetarios y fiscales eficientes para influir sobre la demanda de consumo privado, que se ajuste al pleno empleo; por esta razón, el modelo no representa el comportamiento del ahorro, ni el gasto del gobierno. De esta forma, se estructura el siguiente modelo, según De Haan (1998):

$$
\begin{aligned}
X_{s} & =f(\bar{l}, \bar{k}) \\
\omega & =\partial X_{s} / \partial l \\
\rho & =\partial X_{s} / \partial k \\
y l & =\omega \bar{l} \\
y k & =\rho \bar{k} \\
i & =i \bar{k} \\
c & =X_{d}-I
\end{aligned}
$$

El modelo plantea que la producción está determinada por la demanda y asume un escenario con exceso de demanda en el consumo. Para reducir tal exceso, el autor introduce un impuesto al consumo privado, el cual puede ser un impuesto directo (renta) o indirecto (impuesto de ventas). El impuesto $(t)$ se agrega como una variable endógena, que se ajustará según se necesite para eliminar 
el exceso de demanda, como se muestra en la última ecuación del modelo (62). Johansen (1960) explica que los ingresos, por concepto de impuestos, son usados para financiar el descenso del nivel de la inversión total, con inversión pública (I).

Este modelo describe a grandes rasgos, a una economía centralizada (Noruega), que tiene como objetivo un rápido crecimiento e industrialización de su economía; por lo cual, presenta un alto nivel de inversión fijado a la capacidad de capital (ecuaciones 61 y 62) y con una inversión pública (1), inclusive más allá del punto que la población está dispuesta a aceptar y soportar. Una economía centralizada, a criterio de Johansen (1960), es un buen escenario para demostrar, como utilizando un modelo neoclásico, la asignación de los recursos es regulada por las productividades marginales, situación representada en las ecuaciones 59 y 60.

Johansen (1960) planteó una teoría neoclásica, en la cual se "asume que las tecnologías de producción son del tipo "putty-clay". Esto significa que una vez que el capital es instalado, sus características técnicas, incluyendo la cantidad de trabajo empleada por unidad de capital, permanecen constantes durante su vida de servicio" (Soto, 2008, p. 59). De esta forma, asume una equivalencia entre productividad marginal y la teoría del valor trabajo en un sistema de competencia perfecta (Johansen, 1960), al fijar el salario y determinar todos los precios del mercado en función del valor de este último, fija el salario (ecuación 57) y expresa todos los precios en términos de este. Con esto, se podría fijar el precio de cualquier bien y expresar todos los precios del mercado en términos de este bien numerario.

Adicionalmente, Johansen (1960) diferenció todas las ecuaciones de acuerdo con el tiempo y linealizó el Modelo de Equilibrio General, al aplicar logaritmos, transformando las variables, para resolver el modelo, en tasas de crecimiento, excepto la demanda exógena, que la utilizó en tasas de crecimiento absolutas. Este procedimiento no afectaría ninguna de las variables reales. De esta forma, obtuvo un sistema de ecuaciones de tasas de crecimiento y calculó la inversa de la matriz de coeficientes del sistema de insumo-producto que construyó, y así resolvió el modelo mediante la simple inversión de una matriz, produciendo tasas de crecimiento de las variables endógenas (Arrow \& Debreu, 1954). Otro detalle importante es que, en este tipo de modelos, tradicionalmente, la demanda final es considerada exógena. Con esta condición, se busca mostrar los efectos directos e indirectos que pueden causas variaciones de la demanda final, sobre el consumo intermedio de los diversos sectores de producción.

Johansen (1960) realiza el primer intento práctico de unir teoría y realidad, al realizar un modelo de equilibrio general computable, empírico para la economía noruega; con ello, diseñó el primer modelo de este tipo, el cual era simple y se podía resolver sin mayor nivel de cálculo (O'Ryan et al., 2000).

El modelo se podría cerrar utilizando la técnica neoclásica, como explican Escobar-Espinoza et al. (2017):

La inversión es endógena y determinada por el nivel de ahorro. Se podría usar el cierre Keynesiano, que permite desempleo, la oferta laboral seria endógena. El cierre de Johansen es un punto intermedio: mantiene las consideraciones neoclásicas de la oferta pero mantiene un nivel de inversión exógena. En el caso del cierre Kaldoriano se considera un mecanismo de distribución del ingreso (p. 540). Como se analiza en el siguiente modelo.

\section{Modelo de Kaldor}

"El modelo de Kaldor (1955) introduce la distribución funcional del ingreso al modelo de Harrod-Domar, para mostrar que el crecimiento equilibrado con pleno empleo, es posible en la economía" (Jiménez, 2011, p. 310). Es un modelo de tipo poskeynesiano, en el cual los ingresos pueden dividirse en dos grandes categorías: salarios y beneficios (ecuaciones 64 y 65). Contempla 
diferentes propensiones marginales a consumir (o ahorrar) y asume que los capitalistas ahorran más. La distribución del ingreso depende de la relación inversión - producto dadas las ecuaciones 65 y 67. Considera la hipótesis keynesiana de que la inversión puede tratarse como una variable independiente de los cambios, en las dos posibilidades de ahorro. Lo que implica que el nivel de precios en relación con el nivel de los salarios está determinado por la demanda (ecuaciones 64 y 68): un aumento en la inversión incrementará los precios y los márgenes de ganancias, y reducirá el consumo real, mientras que, con una caída en la inversión, disminuyen los precios y un aumento en el consumo real, suponiendo precios flexibles. Conforme el precio fluctúe, ante los cambios de oferta y demanda, igual que en el modelo de Keynes (Sen, 1963), el salario real disminuiría para mantener el equilibrio, hasta al punto que la demanda $y$ la oferta total se igualen.

Utiliza la hipótesis del crecimiento neoclásico, pero sin considerar sus elementos microeconómicos, es un rasgo particular de este tipo de modelo. (Kaldor, 1955). El modelo es según De Haan (1998):

$$
\begin{aligned}
x_{s} & =f(\bar{l}, \bar{k}) \\
y l & =(w / p) \bar{l} \\
y k & =X_{s}-y l \\
c & =\gamma 1 y 1+\gamma k y_{k} \\
i & =\imath \bar{k} \\
x_{d} & =c+i \\
x_{s} & =X_{d}
\end{aligned}
$$

Kaldor (1955) considera que el ajuste entre oferta y demanda es un proceso dinámico, en el cual, el nivel de precios gradualmente aumenta para eliminar el exceso de demanda, debido al mecanismo de ahorro forzado, establecido en el funcionamiento de las ecuaciones 64 y 65 . Es un instrumento de distribución del ingreso del trabajo en favor del capital.

En esta estructura, Kaldor elimina la segunda ecuación del modelo de Johansen (salario real) y convierte al salario en la variable que, ahora ajusta el modelo, aplica la primera regla de cierre (Taylor \& Lysy, 1979). Al igual que en el modelo anterior, mantiene la condición de que la demanda determina la producción, mientras la actividad económica se encuentra en pleno empleo. De esta forma, cualquier aumento de la demanda sería resuelto por el aumento de los precios, que disminuirían el salario real y se podría capturar el ahorro forzado cada vez que aumenten los precios, lo cual aumenta el ingreso del capital como se muestra en la ecuación 65 (Kaldor, 1955).

El mecanismo de ahorro forzado funciona de esta forma: cada vez que aumentan los precios, disminuye en términos reales, el pago nominal del salario, y como el ingreso del trabajador está definido, como el residuo de la producción una vez pagado los salarios, estos deben bajar y el ingreso del capital aumenta, se ahorra gastos en salarios y puesto que el precio se ajusta a los cambios de oferta y demanda, además involucra a la inversión, así si existiera un exceso de inversión el mecanismo de ahorro forzado sería intensificado, los precios subirían para capturar el ahorro requerido para alcanzar de nuevo el equilibrio. El proceso de ahorro forzado redistribuiría el ingreso del salario en favor del capital. (Andic, 1962).

El modelo de Kaldor tiene otra característica particular: el ingreso del capital incrementa, mientras la propensión a ahorrar del capital decrece. Este mecanismo es llamado el cruce de 
viudas (Nagatani, 1981). Este se evidencia al introducir un impuesto sobre los beneficios (renta). Se disminuye el consumo inducido por las variaciones de la renta; provocando un decrecimiento en la pendiente de la curva de demanda, debido a que la propensión marginal a consumir del capital depende del beneficio real disponible, una vez deducidos los impuestos (Sadoulet \& Janvry, 1995).

Por ejemplo, si se introduce un impuesto y los ingresos generados por este son utilizados como un subsidio a los pobres, se experimenta una modificación en el nivel de producción, que provocaría tanto una disminución en el consumo, como en la demanda agregada, que sería compensado por el aumento del consumo por el subsidio a los pobres, pero se alcanzaría un nuevo equilibrio con un nivel de producción menor, se reduce la inversión. (Kaldor, 1955).

Kaldor (1955) analizó cómo los impuestos sobre las ganancias, la herencia, el capital, los dividendos, entre otros, tienen diversos efectos (en general, mínimos) sobre el gasto y denominó eficiencia económica al efecto restrictivo del gasto neto de un impuesto. Los impuestos al gasto $y$ asociados a una distribución equitativa del ingreso y a un bajo grado de desigualdad permiten una mayor tasa potencial de ahorro y, mientras existan estímulos para invertir, habrá mayor acumulación de capital y, por ende, crecimiento. Este círculo virtuoso se mantendrá siempre que los ricos no desalienten su ahorro para estimular su consumo, por ejemplo, como resultado de un impuesto a la renta.

\section{Modelo de Kalecki competencia oligopolística}

El modelo macroeconómico de Kalecki tiene una base microeconómica más útil que el anterior, a criterio de Taylor y Lysy (1979), que le permite explicar cómo se forman los precios industriales con márgenes de ganancia $(\pi)$ sobre los costos (ecuación 70) y distinguió entre los precios determinados, tanto por los costos, como por la demanda (ecuaciones 75, 76 y 77). Su teoría deriva significativamente de la estructura Keynesiana, su modelo funciona similar. Las diferencias surgen, al considerar el nivel de precios, que puede ser constante e incluso puede disminuir, al mantenerse la capacidad productiva; provocando que, mientras un incremento en la demanda efectiva conduciría a que la producción y el nivel de precios aumenten en la estructura de Keynes, en el modelo de Kalecki únicamente el volumen de producción aumenta (De Haan, 1994). Sin embargo Kalecki utiliza el multiplicador del gasto de Keynes.

Kalecki (1956) considera la economía como un oligopolio, donde las firmas tienen el poder de fijar sus precios. La intensidad del grado de monopolio (aunada a otros factores de la distribución) es clave para la determinación de la distribución macroeconómica. Los factores de la distribución son esencialmente pertinentes para la demanda efectiva y para las fluctuaciones de la producción agregada, y de la utilización de los recursos. Kalecki (1956) trató de desarrollar una teoría que integrara los procesos de crecimiento con los procesos cíclicos de la economía capitalista, "a través del impacto que tiene en la distribución del ingreso y la inversión. Y es justamente en relación con esas ideas que, se ha convertido en un referente importante para la economía heterodoxa, en particular para la poskeynesiana" (Anaya Díaz, 2014, p. 115).

Parte de una relación lineal, entre empleo y el nivel de producción (De Haan, 1994). El trabajo es asumido como variable y la capacidad productiva es subutilizada, como consecuencia de la conducta oligopólica, para prevenir la fácil entrada al mercado de nuevas firmas. Mantiene el supuesto de Kaldor sobre la propensión a ahorrar, la cual es considerablemente menor para los asalariados que para los receptores de ganancias (Agénor \& Montiel, 2015). La estructura del modelo sería según De Haan (1998): 


$$
\begin{aligned}
& p=(1+\pi) \bar{\omega} \lambda \\
& v=X_{s} / \bar{k} \\
& \omega=(\bar{\omega} / p) \\
& 1=\lambda X_{s} \leq \bar{l} \\
& y 1=\omega 1 \\
& y k=\pi \omega 1 \\
& c=\gamma 1 Y 1+\gamma \mathrm{k} y_{k} \\
& \iota=f(\rho \mathrm{e}, v) \\
& X_{d}=c+i \\
& X_{s}=X_{d}
\end{aligned}
$$

La demanda de inversión, en el modelo, es la tasa de crecimiento del stock de capital ( $\iota)$, el cual es determinado por las expectativas de ganancias en el futuro ( $\rho$ e) y el grado de utilización de la capacidad productiva, que es indicada por el coeficiente producto-capital ( $v=X_{s} / \mathrm{k}$ ) (Kalecki, 1956). Lo que significa que $\mathrm{v}$ representa el costo del capital y el nivel de producción real depende del valor de los parámetros $(c+i)$. Estas formulaciones demuestran, por ejemplo, que una contracción de la economía baja la producción y la inversión.

Por ejemplo, si la economía se acercara al nivel de pleno empleo, el producto real no se incrementaría más allá que el ingreso nominal, al elevarse el nivel de precios, esto ocurre porque el multiplicador real cambia a un multiplicador monetario, dejando al ingreso real y al empleo sin cambio, como se muestra en las ecuaciones 72 y 73 (Taylor \& Lysy, 1979). En principio, no hay límite a la demanda de inversión o cualquier otra categoría de demanda exógena, puesto que la producción se expandirá y generará el ahorro para financiar el incremento de la demanda efectiva, hasta que el pleno empleo es alcanzado.

En caso de encontrase la economía en pleno empleo, el modelo se resolvería con el uso del cierre de Kaldor (Taylor \& Lysy, 1979), la inflación desgastaría el ingreso real de los trabajadores y provocaría que el ingreso del capital varíe. El margen de ganancia $(\pi)$ sería, entonces, una variable endógena. Se debe tener presente que, en este modelo, también funciona el ahorro forzado y el mecanismo de cruce de viudas. El modelo, además, permite la incorporación del gasto público, como una variable de ajuste. El cierre del modelo se lograría aplicando la segunda y tercera regla de cierre.

En el modelo kaleckiano, la demanda está determinada por la relación de los salarios, con la propensión a consumir de los diversos agentes, y estos, a su vez, con el grado de monopolio. De esta forma, "la demanda produce los incentivos y las necesidades de inversión, además que genera $y$ explica los movimientos del producto y el empleo, creando una interacción circular entre los diferentes componentes señalados" (Pérez Rodríguez, 2011, p. 16). Es un modelo de crecimiento basado en la demanda, en el que la distribución del ingreso está completamente endogenizada.

El concepto de grado de monopolio constituye un elemento microeconómico esencial del desarrollo macroeconómico de Kalecki, en especial, para el abordaje de la demanda efectiva y los 
cíclico económicos, por medio de la distribución del ingreso y la inversión. Es un planteamiento fundamental de la teoría poskeynesiana.

\section{MODELOS CON UNA ECONOMÍA ABIERTA}

La economía abierta describe a un país con comercio exterior. Los modelos que se crean bajo estas condiciones se interesan, entre otras cosas, en los flujos de capital de entrada y de salida de un país, en cómo se obtiene el nivel de renta y de acumulación del capital, el comportamiento de los salarios reales, los márgenes de beneficio y la inflación. Para realizar tales análisis, se requiere desagregar la demanda, otra vez, con el fin de analizar, cómo se ve afectada, por cambios que experimenten los factores que la determinan. Todos estos estudios forman parte de la macroeconomía de una economía abierta.

Los modelos de una economía abierta son más realistas sobre las verdaderas condiciones macroeconómicas de un país en particular. La economía cerrada es un ejercicio para simplificar y entender mejor la macroeconomía. Con la abierta si es posible visualizar el flujo de importaciones y exportaciones, que implica considerar variables claves, como los tipos de cambio, la balanza de pagos o la balanza por cuenta corriente.

Se consideran únicamente cuatro modelos de la sección anterior: Walras, Kaldor, Keynes, como los de mayor envergadura en los modelos macroeconométricos y Marx, como el clásico alternativo.

\section{Modelo marxista}

El modelo marxista resalta la importancia de distribuir la rentabilidad, la producción y la inversión, las cuales se determinan por las decisiones que se tomen con respecto a los beneficios esperados. Con este modelo, Marx trasciende del análisis de la teoría del valor a la teoría de la acumulación. "La propuesta de Marx está orientada a desarrollar la economía política de la economía mundial sobre la base de las categorías fundamentales: valor, plusvalía, tasas de ganancia, etc. y reproducción de la economía mundial" (Caputo Leiva, 2012, p. 308).

La producción está organizada y determinada por la distribución. "Marx se apropió de los conceptos clásicos del valor trabajo y del valor de los bienes y con ellos, se equipó para ofrecer una interpretación alternativa de la producción y la distribución” (Furio Blasco, 2005, p. 145) en el modo de producción capitalista. El análisis del modelo de economía abierta marxista se fundamenta en la acumulación ampliada del capital.

La acumulación es la reproducción del capital en una escala progresivamente creciente. En este modelo la reproducción simple (modelo de economía cerrada), es alterada su estructura y cambia para mostrar la escala mayor a la que crece la reproducción, el capital original continúa reproduciéndose y produciendo plusvalía. Esta es convertida en capital únicamente porque el producto excedente, ya comprende los elementos materiales del nuevo capital, es decir, el capitalista requiere mano de obra adicional (ecuación 84). Si la explotación de los trabajadores ya empleados no aumenta, ya sea de manera extensiva o intensiva, entonces se debe encontrar fuerza de trabajo adicional. Para esto, el sistema capitalista proporciona un mecanismo: convertir a la clase trabajadora en una clase dependiente de los salarios, que son suficientes, no solo para su mantenimiento, sino para su aumento. Considerando esta dinámica, el modelo pretende describir la ley económica de la sociedad capitalista (Marx, 1980, Tomo III), es decir la ley general de la acumulación capitalista.

En el modelo, el salario es fijo tanto en términos nominales, como reales (ecuaciones 82 y 83), una condición que posteriormente el pensamiento tradicional de la corriente neoclásica lo retomará 
(De Haan, 1998). Los precios son también fijos por el supuesto de la ley de un único precio, el precio interno ( $p$ ) es igual al del mercado mundial $\left(\bar{\theta} \bar{p}^{*}\right)$, por eso el salario se fija en términos reales (Sargent, 2015). No se acepta el pleno empleo, este está determinado por el nivel de producción y un stock de capital dado (ecuación 81); además, se ve afectado por el plusvalor (V), los precios y el salario, que está en función del nivel de producción con un coeficiente constante $(\mathcal{V})$. La siguiente estructura moldea las discusiones anteriores:

$$
\begin{aligned}
& p=\bar{\theta} \bar{p}^{*} \\
& X_{s}=f(1, \bar{k}) \\
& w=\bar{w} \\
& y 1=\omega 1 \\
& V=\mathcal{V} X_{d} \\
& c=\left(\gamma 1 y_{1}+\gamma k y \mathrm{k}\right) / p \\
& Y=p y \\
& i=\left(\sigma_{1}+\sigma_{\mathrm{k}}\right) \bar{k} \\
& X_{d}=c+i-(m-e) \\
& X_{s}=X_{d}
\end{aligned}
$$

En la dinámica del modelo, una elevación del salario nominal implica un incremento en el real $y$, por consiguiente, reduciría la demanda por trabajo y esto causaría una caída en el plusvalor y en la producción (ecuaciones 81 y 84). Se disminuiría, también, el ingreso del capital, disminuyendo la inversión y el consumo por parte del capital (Erice Sebares, 2013). En el análisis clásico y en el marxista se brindan explicaciones muy diferentes en relación a los salarios. Los clásicos postulaban que los ajustes se debían a cambios en la oferta de "trabajo en el mercado, las mejoras en los salarios reales llevarían a un incremento de la fuerza de trabajo y acabaría bajando las tasas salariales. Marx consideraba que el ajuste procedía de la demanda de la fuerza de trabajo". (Furio Blasco, 2005, p. 148), como se muestra en modelo anterior, la demanda de trabajo es variable, se ajusta según los niveles de producción (ecuación 81). "Wade (1833) explica que, si la tasa del salario aumenta tanto que la ganancia del patrón desciende por debajo de la ganancia media, éste deja de ocuparlos o sólo los ocupa a condición de que acepten una reducción de los salarios”. (Marx, 1980, Tomos I, p. 767).

La inversión disminuiría, también, debido a que $\sigma_{k}>\sigma_{l}$ (ecuación 87), la elasticidad de sustitución del capital es mayor que la del trabajo, lo que implica que es más fácil sustituir trabajo por capital que viceversa, supuesto que asume Marx (Marx, 1980, Tomo II y III), haciendo que disminuya la tasa de crecimiento por la caída de la inversión.

Al desagregar el coeficiente de la función de inversión (exógena) ecuación 87, con esta condición genera una nueva regla de cierre: incluir una ecuación independiente al modelo, y agrega una variable endógena (segunda regla) el plusvalor (ecuación 84) de esta forma cierra el modelo.

El modelo presenta, en un primer momento, una ambigüedad en el efecto sobre el consumo, este tiende a disminuir por la caída de la inversión y por la disminución del ingreso, ya que $\gamma \mathrm{l}>\gamma \mathrm{k}$ 
y $y_{l}>y_{k}$. Al presentar el modelo una sustitución menor que uno, implica que la parte de salario incrementa, pero el ingreso real del trabajo disminuye (De Haan, 1998). El efecto negativo de un incremento o un decrecimiento en la demanda de trabajo es más grande que el efecto positivo del aumento del salario y, por lo tanto, el consumo privado disminuye, también porque la propensión a consumir del trabajo es mayor, que la del capital (De Haan, 1998), como muestra la ecuación 85.

El capitalista obtiene en el mercado la fuerza de trabajo que necesita, se apodera de su valor de uso, es decir, su tiempo de trabajo, pero coexiste una distinción a saber sobre el valor de cambio de la fuerza de trabajo (Yl) y el valor de uso (w), pero de ambos se apodera el capitalista, lo que origina la extracción de la plusvalía. Además, la relación que existe entre plusvalía y el valor de la fuerza de trabajo brinda las bases de la tasa de explotación (Morishima, 1973). La tasa de plusvalía, medida por "la división de la renta entre salarios y beneficios y la estructura tecnológica expresada por la composición orgánica del capital (medida por la relación capital/producto o capital/salarios" (Gigliani, 2007, p. 4), estructura la acumulación ampliada del capital (ecuaciones de la 83 a 87).

Solo el trabajo genera plusvalía y en consecuencia beneficio. Condición que se amplía constantemente, por la competencia que el ejército industrial de reserva (desempleados) provoca entre los trabajadores para obtener un empleo, situación que logra mantener a un nivel de subsistencia los salarios (Mandel, 1974), además de mantener la diferencia entre los valores de cambio y de uso de la fuerza de trabajo. Por otra parte, los recursos productivos y la fuerza de trabajo conforman el capital y, a su vez, la inversión capitalista.

Gracias al comercio exterior, con las importaciones se permite crear "una masa de mercancías que se transforman en productos de lujo $y$ en productos de consumo comunes y corrientes, provocando una caída general de los salarios y un alza considerable de las ganancias" (Mandel, 1974, p. 29), al ser depreciados los costes del capital constante, así como los medios de subsistencia de los trabajadores. De esta forma, se aumenta la tasa de ganancia, al bajar el valor del capital constante y crecer la tasa de plusvalía (Erice Sebares, 2013). La plusvalía es la que abastece el consumo individual del capitalista, al ser su ingreso el cual acumula y se convierte en capital. Por consiguiente, dada una masa de plusvalía, cuanto mayor es una de estas partes, más pequeña es la otra, la proporción de estas partes determina la magnitud de la acumulación (Marx, 1980, Tomo I).

Los marginalitas abandonarán la idea de la plusvalía, como proceso de acumulación del capital. Al centrarse en la asignación de los recursos y no en la producción, se invisibiliza el papel del proceso de trabajo en la dinámica del capitalismo (Furio Blasco, 2005).

Los clásicos consideraban que la acumulación es generada por la rentabilidad, la cual es "una variable endógena, tanto en el corto y como en el largo plazo. Por lo cual, un sistema capitalista puede mantener niveles crecientes de ganancias, por períodos, lo que permite mantener tasas de acumulación sostenidas" (Gigliani, 2007, p. 3). Conclusión que Marx refutó y demuestra que es la plusvalía la que logra la acumulación, no una mayor rentabilidad.

El pensamiento de Marx, compartido por el resto de los clásicos, sobre la distribución de la producción y del ingreso, en salarios, ganancias y renta, es abandonado en el pensamiento económico posterior, lo remplazan por una distribución individual (familiar) del ingreso, que "oculta el origen del ingreso: como salario, como ganancia o renta de recursos naturales. Esta idea surge de la teoría neoclásica, que se centra en los individuos, el consumo, y la soberanía del consumidor como determinantes de la economía” (Caputo Leiva, 2012, p. 313).

Marx elabora un modelo de las preferencias del consumidor y, además, elimina el postulado de pleno empleo y el crecimiento a plena capacidad y mantiene la necesidad del sistema capitalista, de una acumulación cíclica del ejército de reserva de mano de obra, por eso su modelo es una aproximación a la rigidez de los salarios. Es un modelo de equilibrio general de producción, apropiado para analizar una sociedad en un entorno capitalista, a criterio de Morishima (1973). 


\section{Modelo de Walras}

Es un modelo de teoría neoclásica general que incorpora criterios clásicos, con partes del analálisis de lo que posteriormente se conocerá como pensamiento keynesiano y neokeynesiano, para describir la economía actual, como la ecuación de ingreso total $(Y)$. Walras desarrolló una estructura de equilibrio general, que trasciende de la representación abstracta de la economía, a una más realista.

Walras (2014) analizó el intercambio y la producción de bienes de capital fijo (ecuación 91), en una estructura matemática, con la cual ofrece un análisis de las relaciones simultáneas entre todas las variables económicas. Fue el primero en expresarlas, mediante un sistema de ecuaciones simultáneas, que permitió descubrir ciertos teoremas fundamentales, como la teoría del intercambio y los precios relativos, por eso fija lo electos de la oferta (ecuación 91). Con esta teoría, postula que para resolver las curvas de demanda y oferta de un producto, es necesario tener en cuenta todos los mercados de bienes y servicios disponibles (Bridel, 1997).

Con su modelo, se obtiene un equilibrio en el cual tanto los consumidores, como los productores no tienen ningún interés en moverse del nivel logrado, esta condición se considera normal, las unidades de bienes y servicios que se demandan o que se ofrecen en los diferentes mercados (ecuaciones 92 y 93), solo se pueden aumentar o disminuir por variaciones exógenas al sistema de intercambio planteado, como se muestra en la ecuación 91, Walras trasciende de su teoría del equilibrio general, hacia una teoría del comportamiento de los agentes económicos (Bridel, 1997).

En el modelo los precios y cantidades son endógenos (ecuaciones 90 y 92) y se ajustan a los cambios de los mercados, que funcionan en condiciones de competencia perfecta, por lo cual los recursos son asignados de forma óptima y los agentes son racionales y existe pleno empleo de los recursos, donde el ahorro determina la inversión de la economía (O'Ryan et.al., 2000). Mantiene, en el régimen de comercio exterior, la ley de un único precio, esto es el precio interno ( $p$ ), que es determinado por el precio del mercado mundial $\left(\bar{\theta} \bar{p}^{*}\right)$ (Taylor \& Lysy, 1979), ecuación 90, como en el modelo de Marx.

Se estructura a un país pequeño, en el cual se puede exportar e importar cualquier cantidad al precio fijado, lo que implica que cualquier exceso de demanda u oferta, puede ser eliminado por un ajuste cuantitativo de las importaciones netas ( $m$ - e), ecuación 95 (Bridel, 1997).

Si el ex-ante ahorro de oferta excede al ex-ante inversión de demanda, el exceso es eliminado por un decrecimiento en importaciones netas, considerado ahorro externo y un exceso de demanda es enfrentado por un incremento en importaciones netas (Morishima, 1977). En comparación con el modelo cerrado, donde el nivel de precios fue dejado indeterminado, ahora con la ley de un único precio, el nivel de precios interno es fijado. Con estas condiciones, se presentada el siguiente modelo según De Haan (1998):

$$
\begin{aligned}
p & =\bar{\theta} \bar{p}^{*} \\
X s & =f(\bar{l}, \bar{k}) \\
Y & =p y \\
c & =\gamma Y / p \\
i & =\iota \bar{k} \\
X_{d} & =c+i-(m-e) \\
X_{s} & =X_{d}
\end{aligned}
$$


Es importante notar que el modelo no puede ser cerrado si se abandona el régimen de tipo de cambio nominal fijo. En ese caso, por eso el tipo de cambio real $(\theta / p)$ es fijado (ecuación 90 ). Esto es fácilmente demostrado con la desagregación de la ecuación 94, el balance de ahorro e inversión:

$$
i=\sigma y+(m-e)
$$

Si el tipo de cambio nominal $(\theta)$ no es fijado, la ecuación anterior no contiene ninguna variable endógena, que podría afectar tanto al ingreso, como al ahorro real y no se podría obtener un equilibrio, no habría ninguna incidencia en el modelo ante cambios en el tipo de cambio (Morishima, 1977).

La base anterior le permitió a Walras, un primer acercamiento al intercambio sectorial con comercio exterior, dadas sus limitaciones, desagrega el nivel de ingreso (ecuación 92) para modelar una economía más real.

De esta forma, si la ley de único precio se abandona, el modelo es más complejo. El precio de venta de una unidad de producción en el mercado interno sería diferente del precio de una unidad de exportación (ecuación 98 y 100). Similarmente, el precio de compra de una unidad de producción en el mercado interno difiere del precio de compra de las importaciones. Por ejemplo, si el precio interno es superior al del mercado mundial, eso provoca que las exportaciones netas disminuyan, para frenar las exportaciones o aumentar importaciones, con los ajustes mencionados se formula un nuevo modelo, según de De Haan (1998):

$$
\begin{aligned}
p_{w} & =\bar{\theta} \bar{p}^{*} \\
X_{s} & =f(\bar{l}, \bar{k}) \\
Y & =p(y+m-e)-p w(m-e) \\
c & =\gamma Y / p \\
i & =\iota \bar{k} \\
X_{d} & =c+i-(m-e) \\
X_{s} & =X_{d}
\end{aligned}
$$

Dos ecuaciones son cambiadas, la 98 y la 100. La primera define el precio del mercado mundial equivalente en divisa local y la tercera ajusta el ingreso total, para diferencias entre precio interno y el externo. La ecuación de balance entre ahorro inversión sería:

$$
i=\sigma(Y+m-e)+(1-\sigma)(\theta / p) p^{*}(m-e)
$$

En contraste al régimen de un único precio, ahora bajo un tipo de cambio fijo y con exportaciones netas ( $m$ - e), el precio puede actuar, en principio, como una variable de ajuste. Pero eso sería solo en caso de un superávit comercial, es decir que (m - e) < 0 (Sadoulet \& Janvry, 1995). En caso de un déficit comercial, al mantener la función de inversión independiente hace el modelo inestable. Un exceso de demanda de inversión no puede ser eliminado, por un aumento en el nivel de precios. Las diferencias en el balance entre ahorro e inversión, con respecto a los precios, daría como resultado que el exceso de demanda únicamente se incremente con una elevación en el nivel de 
precios internos $\left(p_{w}\right)$ (Morishima, 1977), causando inflación; en este caso, al igual que el modelo de Marx, se utiliza una función de inversión independiente, con la cual cierra el modelo.

Por otra parte, existe una ganancia en ahorro privado interno (parte derecha de la ecuación 105), pero es más que compensado por un menor ahorro externo. Por eso en el modelo cerrado, la ecuación de inversión tenía que ser eliminada. Bajo un tipo de cambio flotante, la situación cambia, entonces un ajuste sería posible con el tipo de cambio real, con el precio interno fijo como un numerario, el tipo de cambio nominal actuaría como variable de ajuste.

En caso de un déficit comercial, un exceso de demanda de inversión sería eliminado por una devaluación, es decir, un aumento del tipo de cambio nominal ( $\theta$ ); mientras un exceso de ahorro puede ser enfrentado con una revaluación o decrecimiento de $\theta$. Una devaluación (revaluación) implica un incremento (decrecimiento) del tipo de cambio real (Bridel, 1997). En caso de un superávit comercial, el modelo sería incompatible con una ecuación que determine independientemente la inversión, ya que el tipo de cambio nominal es una variable política, el gobierno puede actuar en tal situación con un apropiado ajuste de $\theta$. Un exceso de inversión, por ejemplo, sería resuelto por un decrecimiento del tipo de cambio nominal.

El modelo de Walras de una economía abierta, es un modelo de equilibrio general neoclásico, que asume una economía en equilibrio con pleno empleo, que se ajusta por medio de los mercados competitivos, consiguiendo un equilibrio macroeconómico, que integra la teoría del equilibrio microeconómico (Furio Blasco, 2005, p. 193).

\section{Modelo de Keynes}

Es un modelo de fluctuaciones basado en el supuesto de la existencia de barreras que, dificultan el ajuste instantáneo de los precios y salarios nominales. Esta lentitud del ajuste nominal, hace que los cambios en la demanda agregada de bienes a un nivel dado de precios, influyan en la cantidad que producen las empresas. Como consecuencia de esto, las perturbaciones meramente monetarias (que afectan sólo a la demanda), pueden provocar cambios en los niveles de empleo y de producción. Además, hay muchas perturbaciones de naturaleza real (incluidos los cambios en el volumen de gasto público en la demanda de inversión y en la tecnología), que afectan a la demanda agregada existente a un nivel dado de precios (Romer, 2006, p. 225).

Keynes realiza su análisis desarrollando los conceptos de demanda y oferta agregada, con los cuales observa el funcionamiento de variar variables, entre ellas el dinero, el consumo, la inversión, el gasto público y las condiciones financieras internacionales en una economía abierta. "Las mismas interactúan y afectan de diversas formas la actividad económica de un país, alterando sus niveles de producción, de precios, impactando el tipo de cambio y con ello, la balanza de pagos y las reservas internacionales" (Castillo More, 2010, p. 87). De esta forma, consiguió moldear instrumentos de política económica a nivel monetario, cambiario y fiscal, para impulsar el crecimiento económico y lograr un mayor empleo.

El modelo no asume pleno empleo, como el anterior "Keynes sostenía que el libre mercado carece de mecanismos de auto-equilibrio que lleven al pleno empleo, por eso justifica la intervención del Estado, mediante políticas públicas orientadas a lograr el pleno empleo y la estabilidad de precios" (Jahan et al., 2014, p. 53).

La ley de un único precio no se aplica en este modelo. Existe una diferencia entre precio doméstico y el del mercado mundial, por lo cual transforma la ecuación 106 del modelo de Marx y la ecuación de inversión es fijada exógenamente (ecuación 113); además, elimina la ecuación de inversión de Marx y de Walras (De Haan, 1998). De esta forma, se crea una nueva regla, el modelo exogeniza una ecuación y aplica la primera regla (elimina ecuaciones). 
Keynes transforma los modelos anteriores y agrega otras variables y ecuaciones, que según él son indispensables para analizar y comprobar la efectividad de la política económica en el impulso del crecimiento. Su análisis lo realiza asumiendo un aumento del salario nominal, que conlleva a un exceso de demanda (ecuación 107), lo cual conduce a un aumento de los precios internos $\left(p_{x d}\right)$, pero el nivel de precios agregado aumentaría más rápidamente que estos últimos, ya que estos están determinados por el salario (Sen, 1963). Un cambio en el nivel de salario nominal sería transferido al precio de valor agregado $\left(V=\mathcal{V} X_{d}\right)$. La estructura del modelo es según De Haan (1998) sería:

$$
\begin{aligned}
\varepsilon & =\theta p^{*} / p_{x d} \\
X_{s} & =f(1, k, i, \varepsilon, r) \\
w & =w / p_{x d} \\
1 & =f(w, r) \\
y 1 & =\omega l \\
y k & =i k \\
Y & =p(y+m-\mathrm{e})-p_{w}(m-\mathrm{e}) \\
i & =\tau \\
r^{*} & =f(V, \pi) \\
V & =v X_{d} \\
c & =\gamma 1 Y 1+\gamma k y k \\
X_{d} & =c+i-(m-\mathrm{e}) \\
X_{s} & =X_{d}
\end{aligned}
$$

El nivel de precios seguiría elevándose $y$, finalmente, conduce a un bajo costo del salario real y una alta producción. Cuando se alcanza un nuevo equilibrio el salario real es menor y, tanto la producción como el nivel de empleo, han aumentado (ecuaciones 107, 108 y 109). Debido a estos cambios, se da una disminución del salario real ante un aumento del salario nominal, provocando una disminución en el ingreso de los trabajadores, mostrado en la ecuación 110 (Taylor \& Lysy, 1979).

Ante un aumento del salario nominal, el ahorro privado también incrementa, porque a pesar de que los precios domésticos crecen, los precios agregados crecen más rápidamente y como tanto el ingreso del trabajo, como del capital están determinados por el precio de valor agregado (V) (De Haan, 1998). Compensando y superando el aumento de los precios domésticos, esto se demuestra al ver las ecuaciones (106, 108 y 112) del modelo Keynesiano.

Por otra parte, el ahorro del gobierno disminuye debido al aumento de los precios internos, las exportaciones aumentan por el crecimiento de la producción, que conlleva el aumento del salario nominal (Taylor \& Lysy, 1979), a pesar de que el ingreso disponible compensa el aumento de los precios, disminuye por el aumento de las exportaciones netas y la disminución del gasto del gobierno, mientras el ahorro externo decrece por el aumento de los precios internos. 
Con un tipo de cambio flexible en la economía abierta, la demanda agregada se desagrega en un sistema de tres ecuaciones, con tres incógnitas: el tipo de interés (r), se asume que $r=r^{*}$ es igual a la tasa de interés externa, producción $(Y)$ y tipo de cambio real $(\mathcal{E})$; logrando el cierre del modelo, utilizando la segunda regla, agrega variables endógenas. Con movilidad imperfecta de capitales y tipo de cambio flexible, un incremento del gasto público desplaza la demanda agregada en una cuantía inferior que en el caso de economía cerrada (ecuaciones 114 y 115). Esto debido a que un aumento del gasto lleva asociado un aumento de la deuda emitida para financiarlo. Para atraer capital extranjero, habrá que subir el tipo de interés (r). Si sube el tipo de interés, la oferta de moneda extranjera aumenta, lo que dará lugar a una apreciación del tipo de cambio nacional $(\theta)$. Al apreciarse el tipo de cambio, las exportaciones netas caen y con ellas el gasto deseado (ecuaciones 112 y 115) (Taylor \& Lysy, 1979).

De esta forma, por una parte, un aumento del gasto tiene un efecto expansivo sobre la demanda, pero este efecto, se verá parcialmente compensado por la subida de los tipos de interés, que provocará una apreciación del tipo de cambio y una caída de las exportaciones netas. El modelo de economía abierta de Keynes estructura el patrón cíclico de expansión y contracción de la demanda agregada en el sistema capitalista.

\section{El modelo de Kaldor}

El modelo de Kaldor (1980) presenta una estructura postkeynesiana, que integra la distinción entre beneficios y salarios, inspirado por el trabajo de Kalecki (1956); para explicar el proceso de desarrollo de un país y la distribución de la renta, con una tasa de ahorro de la sociedad en forma endógena. El análisis lo realiza con variables agregadas reales y netas.

"El principio del multiplicador keynesiano, que fue creado para explicar el equilibrio en un sistema económico con subempleo, es utilizado en el modelo para determinar la distribución cuándo el producto está dado" (Kaldor, 1955, p. 94), esto se muestra en la ecuación 120. Afirma que es factible mantener un crecimiento equilibrado con pleno empleo. Asume, además, que la demanda $y$ los beneficios son determinados por decisiones de gasto (Kaldor, 1980), como se muestra en las ecuaciones 124 y 126.

Esta situación explica que la oferta de bienes es inelástica a corto plazo y no se afecta por aumentos de la demanda monetaria, la política monetaria es ineficiente en este periodo, no así en el largo plazo, en donde los tipos de interés se ajustan al nivel que determine la tasa de ganancia, que se obtiene de las inversiones. El nivel de precios en relación con el de los salarios, al estar en pleno empleo, se determina por la demanda, considerando las ecuaciones 121, 124 y 126.

Al comparar los dos modelos de Kaldor (1980 y 1955) tenemos que, en el cerrado, el precio está determinado por la diferencia entre oferta y demanda, el salario nominal es exógeno, se ha dejado como la variable de ajuste. El salario real aumenta o disminuye según los cambios de los precios, dado el mecanismo de ahorro forzado que contempla el modelo observado en las ecuaciones 120 y 121 del modelo economía cerrada.

En cambio, en el abierto, el salario es una ecuación fijada a un salario nominal (ecuación 121) y a una tasa constante de aumento de la fuerza de trabajo (ecuación 122). El nivel productivo está determinado por coeficientes fijos (ecuación 120), y la economía crece a una tasa garantizada, por eso la tasa de ahorro e inversión permanecen constantes (ecuación 125). El consumo estaría determinado por el nivel de precios internos (ecuación 124); prácticamente mantiene la estructura del modelo de una economía cerrada. La propensión del ahorro de ingresos por salarios y los de beneficios, respectivamente, están dados (ecuaciones 122 y 123), el precio interno es exógeno, la oferta está fijada y el ingreso del trabajador es una proporción fija de la demanda de trabajo. La estructura del modelo según De Haan (1998) sería la siguiente: 


$$
\begin{aligned}
& p=\bar{\theta} \bar{p}^{*} \\
& X_{s}=f(\bar{l}, \bar{k}) \\
& w=w \\
& y 1=\omega \bar{l} \\
& y k=p X_{s}-y 1 \\
& c=(\gamma 1 y 1+\gamma k y k) / p \\
& i=\imath \bar{k} \\
& X_{d}=c+i-(m-e) \\
& X_{s}=X_{d}
\end{aligned}
$$

Al partir el modelo de la distribución del producto en salarios y beneficios, el ahorro agregado se divide entre ahorro de los trabajadores y de los capitalistas. El ahorro de cada uno es igual a su propensión a ahorrar (trabajadores y capitalistas), multiplicado por sus salarios o ganancias, lo cual muestra la participación de los beneficios en el producto. Esta identidad demuestra uno de los principales aporte del pensamiento keynesiano y de Kalecki: "los beneficios de los capitalistas están determinados por su gasto en inversión. De este modo, dadas las propensiones, la participación de los beneficios en el ingreso depende de la inversión como proporción del ingreso" (Jiménez, 2011, p. 311).

Para Kalecki, un equilibrio con pleno empleo es posible si se logra que el capital aumente a una tasa natural de crecimiento, pero según Kaldor esta tasa se logra si "está en función del crecimiento de la productividad y el crecimiento de la población, y la relación capital-producto es constante y que la tasa de ganancia dependa de la tasa de crecimiento y de las propensiones a ahorrar" (Jiménez, 2011, pp. 311-312), situación que muestran las ecuaciones 122, 123 y 124. El modelo funciona solo si las dos tendencias de ahorro difieren y la propensión marginal a ahorrar de las ganancias excede a la de los salarios, (ecuación 124) (Kaldor, 1955).

El análisis supone una balanza de pagos con déficit y una tasa neta de exportaciones fijas, un incremento en los precios sobre el ahorro es ambiguo, mientras en el cerrado un aumento de los precios siempre conduce a un aumento del mecanismo de ahorro forzado, en el abierto depende de que tan fuerte sea el ahorro externo. Si el efecto es positivo, el ahorro forzado es intensificado, ya que el ahorro externo decrece por el aumento de los precios internos. Si la reducción en ahorro externo es más fuerte que el incremento en ahorro doméstico real, resultado de una caída en la parte de ingreso del salario, el ahorro total decrecería y el modelo sería igual de insostenible. Esto implica que, ante las condiciones de exportaciones netas fijas, el ahorro forzado es más intensificado en el modelo abierto que en el cerrado. Kaldor utiliza para cerrar el modelo la regla 2, endogeniza el nivel de salarios y de precios, dejando al ahorro que ajuste el modelo.

Gracias a Kaldor (también a Kalecki), el ligamen entre la teoría de la distribución, la demanda y el crecimiento, se convirtió en uno de los pilares de la economía postkeynesiana (Janvry \& Sadoulet, 2016; Kaldor, 1955, 1980; Kalecki, 1956; Morishima, 1973; Sen, 1963; Solow, 1956, 1957). 


\section{ESCUELAS DE PENSAMIENTO QUE SURGEN DE LA DISCUSIÓN DE LOS MODELOS ANTERIORES}

\section{La escuela clásica marxista}

La teoría "marxista presenta una visión completa de la economía, como interrelación entre producción, distribución, circulación y consumo, acentuando el valor de la mercancía dado por el trabajo." (Chain \& Narodowski, 2009), p. 23), "considerando a los precios del mercado por la cantidad de trabajo que su producción incluye" (Erice Sebares, 2013, p. 8), en conjunto con las condiciones técnicas de producción, es decir, la composición orgánica del capital.

Marx transforma la teoría del valor formulada por Ricardo, al hacerlo, no solo mostró una percepción mucho más aguda de la naturaleza del problema involucrado, sino también mejoró el aparato conceptual de Ricardo a criterio de Schumpeter (1983). Desarrolló los conceptos de capital constante $y$ variable, $y$ con ellos, la composición orgánica del capital. "Todo este nuevo vocabulario, permite el desarrollo analítico desde la teoría del valor a la teoría de la acumulación" (Furio Blasco, 2005, p. 145).

Las sociedades capitalistas no producen para satisfacer necesidades, sino para obtener una ganancia (mayor valor). El marxismo demuestra que este mayor valor se obtiene gracias a la explotación de la fuerza de trabajo, al pagar al asalariado solo lo necesario para reproducir su fuerza de trabajo, es decir, el capitalista se apodera de esta plusvalía y después la reinvierte, creando el proceso de acumulación, característica fundamental del capitalismo.

El marxismo describe a la economía, como un proceso de transformación de la naturaleza y de las sociedades por medio de la producción de mercancías, es una condición cíclica. El modo de producción une, a criterio de Marx, los dos eslabones centrales de cualquier organización social: las fuentes productivas, los medios que hacen posible la producción (tecnología e infraestructura) y las relaciones de producción, que involucra cómo se organiza una determinada sociedad, cómo se dividen las clases sociales, cómo se distribuyen y consumen los recursos. Los cambios en los modos de producción implican un proceso histórico, cada vez que se cambia la forma en que se produce en una sociedad, también lo hace su organización, pasando, por ejemplo, de la esclavitud al modo feudal y de este al capitalista. Esto significa que la historia se desenvuelve como resultado de la lucha de clases sociales al interior de cada economía. Este método de análisis es conocido como el materialismo histórico.

El marxismo realiza sus análisis por medio de la dialéctica, con la cual trasciende de la lógica clásica lineal y a una lógica de lo simple a lo complejo, desarrollando conceptos básicos y abstractos con características complejas, para comprender la dinámica de la sociedad capitalista.

\section{La escuela neoclásica}

El pensamiento de esta escuela se inspira en los aportes de los clásicos, contradice las consideraciones de Marx y acepta que el mercado es el mejor para asignar los recursos. Abandona la teoría del valor-trabajo $y$, en su lugar, considera que existe un valor subjetivo de las mercancías que depende de un dato $y$ de un presupuesto. El dato se refiere a que los bienes son escasos, por lo cual, surge el problema de decidir de acuerdo a la importancia de la necesidad, esta elección se transformaría en el problema económico. El presupuesto es la delimitación a la que está sujeto un individuo por su nivel de renta, por tal razón, el individuo debe clasificar sus propias necesidades, de acuerdo a su importancia, para obtener el más elevado nivel de satisfacción, decisión conocida como 
la racionalidad del consumidor. Introducen, para realizar tal análisis, otro concepto fundamental de su aporte a la ciencia económica, el de utilidad, como la medida de la satisfacción obtenida por el consumo de un bien. Gracias a la introducción de las matemáticas, a la economía, se desarrolla la utilidad marginal, como el medio para cuantificar la satisfacción del consumidor, creando con ello la microeconomía.

De esta forma, los precios están en función de las preferencias de los consumidores, por su afán de conseguir una unidad adicional de un determinado bien, intentando maximizar su utilidad. Por esta situación, consideran que los precios deben de ser flexibles, en todos los mercados, tanto en el laboral, transforman los salarios en un precio más, como el de inversión, por lo tanto, las tasas de interés también deben ajustarse al juego de la oferta y la demanda, que determina el nivel de precios de equilibrio del marcado, lo que hace innecesaria la intervención del Estado. La ley Ley de Say garantiza ese equilibrio y el pleno empleo (Roca Garay, 2010), el mercado crea mecanismos de ajuste automático, que llevarían otra vez al pleno empleo.

Desde esta teoría, se analiza la economía pura y los procesos de asignación de los recursos, pero no la distribución de estos, mediante el método de optimización. La economía se separa de los temas sociales y de la política, y se centra en el análisis del mercado. Los "sujetos ya no pertenecen a clases sociales como lo planteaba Marx, sino que son sujetos racionales, que trabajan o aportan capital para producir según técnicas eficientes, que a cambio reciben una retribución y con ella, son consumidores en el mercado" (Chain \& Narodowski, 2009, p. 28).

Los neoclásicos se fundamentan sobre el supuesto de que el comportamiento agregado de los individuos (que son racionales y maximizan su utilidad), junto a otros agentes, determinan el nivel económico de una sociedad (Sen, 1963). La racionalidad de estos agentes está definida como las mejores decisiones que productores y consumidores pueden elegir, debido a las restricciones a las que se enfrentan (renta) todo en un mercado de competencia perfecta y cada mercado se dirige al equilibrio (Bridel, 1997). "Si el mercado funciona naturalmente y sin intervenciones (del sector público) es capaz de organizar el proceso de producción, distribución y consumo de forma equilibrada". (Chain \& Narodowski, 2009, p. 28).

Por otra parte, "el dinero es solo un medio de pago y es neutral, los valores de las variables reales son independientes de las monetarias: dicotomía clásica y el nivel de precios es proporcional a la cantidad de dinero" (Roca Garay, 2010, p. 46).

Walras es el punto de partida de esta escuela, los modelos de este autor representan a esta escuela de pensamiento, es uno de sus principales exponentes, gracias a la introducción de las matemáticas al análisis económico, se brindan los primeros pasos hacia los modelos macroeconómetricos.

\section{La escuela Keynesiana}

La teoría keynesiana abandona la tesis neoclásica, en donde se afirma que una economía de mercado conduce al pleno empleo, automáticamente, y que las crisis son siempre pasajeras. Keynes considera que al partir de esta primicia, los clásicos no pudieron observar una serie de situaciones que se presentan en una economía, se abandonaron a luz de este gran supuesto. El pleno empleo es solo un caso particular, en un periodo de tiempo específico, se podría estar en equilibrio, pero con desempleo. Por eso, Keynes analiza el sistema económico en general y no solo una parte de él, desarrollando la macroeconomía. Esta nueva visión resalta la importancia y necesidad de la política económica, principalmente, como instrumento para controlar el aumento del gasto público. Por esta razón, esta escuela considera fundamental la intervención del Estado, para alcanzar la estabilidad macroeconómica.

Rechaza "la parábola de la mano invisible de Adam Smith y, sobre todo, de la formalización matemática que de ella hizo León Walras" (Petit Primera, 2013, p. 126). Además, critica la 
racionalidad perfecta y el individualismo de los neoclásicos (Sen, 1963). Explica que, por diferentes condiciones, los agentes no logran maximizar y optimizar sus beneficios o utilidades, no existe prevención perfecta y los agentes son susceptibles de cometer errores e influenciarse entre ellos, no hay racionalidad del consumidor, lo que hay es más incertidumbre, por tanto, no existe la competencia perfecta (Persson \& Tabellini, 1999). De esta forma, surgen las expectativas y los problemas de los resultados esperados. Keynes "creó un enfoque dinámico que convirtió la ciencia económica en un estudio del flujo de ingresos y gastos, y abrió nuevas perspectivas para el análisis económico" (Jahan et al., 2014, p. 53).

La esencia de la teoría de Keynes es el análisis de la demanda efectiva, hoy conocida como los gastos agregados, esta determina el ingreso, la producción y el empleo en una económica determinada y está compuesta por la suma del consumo, la inversión, el gasto del gobierno y los gastos netos de exportación. Junto con el concepto del multiplicador del gasto, los keynesiano analizan el efecto de un aumento del gasto público sobre la economía. Es decir, al incremento mayor a uno por cada unidad monetaria invertida.

\section{La síntesis neoclásica keynesiana}

A partir de los años cincuenta, surge en el análisis económico la integración de la teoría clásica, neoclásica y la keynesiana. La teoría clásica y neoclásica aportan al modelo dos ideas básicas: los agentes económicos son racionales y en la economía existen diversos mercados, en los cuales los precios tienden a ajustarse dependiendo del equilibrio entre la demanda y la oferta. El Keynesianismo brindo el supuesto de salarios y precios rígidos o bien que se ajustan lentamente. A esta combinación teórica se le llamó la Síntesis Neoclásica, que se extendió hasta los años setenta. Algunos autores (Arrow \& Debreu, 1954; Castillo More, 2010; Janvry \& Sadoulet, 2016; Lucas \& Sargent, 1981; Lucas, 1983; Nagatani, 1981), denominan esta época como la edad dorada de la macroeconomía.

En la Síntesis Neoclásica se puede analizar la dinámica de una economía, en equilibrio $y$ desequilibrio. Es descrita como Keynesiana en el corto plazo y neoclásica en el largo. En su pensamiento, los agentes económicos pueden ajustarse a la economía, usando políticas fiscales y monetarias, la primera es más eficiente que la segunda, en el corto plazo, pero en el largo plazo el equilibrio se logra sin la intervención del Estado.

Se fundamenta en la macroeconomía keynesiana y la microeconomía neoclásica. Con la primera, analiza la inflación y el desempleo, en el corto plazo, y recomienda políticas económicas para evitar los ciclos depresivos. Con la segunda, concluye que el capitalismo tiene una dinámica interna que puede obtener un equiparado y estable equilibrio en el largo plazo, por eso, para este período abandona el supuesto de la rigidez de los salarios y precios (Nagatani, 1981). La estabilidad en el largo plazo se logra, también, con la intervención de tipo keynesiana del Estado, implica que se invierte todo lo que se ahorra, como gasto fiscal y, por tanto, se ajusta la tasa de interés.

La macroeconomía de la síntesis neoclásica se fundamenta en el modelo IS-LM de Hicks (1989) y Modigliani (1944), como demostración de la obtención de la demanda agregada y junto con la curva de Phillips, lograron desarrollar una oferta agregada, comparable en el largo plazo, a la teoría neoclásica, considerando salarios flexibles en el mercado laboral; sin embargo, en el corto plazo, son rígidos (Solow, 1957).

La síntesis neoclásica se resume en tres teorías: la teoría de la demanda agregada Keynesiana, la del modelo clásico de oferta agregada y la del ajuste de precios. Con el ajuste de precios, lograron desarrollar un modelo dinámico (Arrow \& Debreu, 1954), en comparación a los modelos estáticos de las escuelas anteriores, dando un gran paso hacia los modelos que hoy se desarrollan (Agénor \& Montiel, 2015; Escobar Espinoza et al., 2017; Hosoe et al., 2010; Sargent, 2015), al considerar la oferta de dinero como un flujo y no como un stock de emisión. 
A estas condiciones, se le agrega una curva de oferta en el mercado laboral, con lo cual crean las bases de una formulación teórica de un modelo neoclásico de equilibrio general, con pleno empleo en el largo plazo, logrado por los mecanismos de mercado competitivos. Con esto, se consigue un avance con respecto a la teoría del equilibrio general microeconómico iniciado por Walras y Pareto (Sargent, 2015).

\section{Escuela postkeynesiana}

La escuela postkeynesiana explica Lavoie "es una de las numerosas escuelas de pensamiento heterodoxo que hay en economía, sus miembros tienen en común el intento de retomar y completar la teoría general de Keynes" (2014, p. 30), desarrollando ciertos conceptos básicos de este autor e incorporando otros nuevos que, a criterio de los postkeynesianos, no fueron completados o han sido dejados de lado por la síntesis neoclásica. Se centran, principalmente, en: la producción, la acumulación y la distribución, de forma agregada, utilizando la demanda efectiva de Keynes, es decir, en la macroeconomía; sin embargo, consideran algunos aspectos microeconómicos.

Los postkeynesianos explican el crecimiento económico, conjuntamente con la distribución de la renta (las consideran directamente relacionadas), por medio del análisis de la tasa de inversión, que según esta escuela es la "variable que determina el crecimiento y la distribución. Demuestran que, en una economía dinámica y expansiva, los efectos renta originados por la inversión y otras fuentes de crecimiento, compensan con creces los efectos sustitución resultantes de los movimientos de precios" (Furio Blasco, 2005, p. 211). Esto significa que los cambios en la demanda agregada y en la sectorial se deben a las fluctuaciones de la renta y no de los precios relativos (Kalecki, 1956), sobre todo en el corto plazo, en el largo, ambos efectos son igual de importantes. Consideran que los mercados son oligopólicos u oligopsonios, en los cuales el agente que tenga mayor poder de mercado fija el precio, considerando el costo medio más un margen de ganancia, que fluctúa según el nivel de actividad económica y el grado de poder de mercado de los agentes (Kaldor, 1955, 1980; Kalecki, 1956). De esta forma, demuestran que las fuerzas del mercado no garantizan que una economía funcione con pleno empleo, el capitalismo no puede automáticamente conseguirlo, se necesita la intervención del Estado para restaurar el pleno empleo, como Keynes indicaba. A su criterio, un mercado sin regulaciones implica reiterados ciclos económicos y alimenta la inestabilidad económica (Lavoie, 2014).

Por esta razón, está escuela rechaza la ley de Say, afirma que la cantidad de producción vendida depende del nivel de demanda agregada, es el principio de la demanda efectiva de keynes, por tanto, la economía está determinada por la demanda y no por la oferta. Por eso, establecen que la inversión determina causalmente el ahorro.

Otro planteamiento es el rechazo, también, al concepto de racionalidad del consumidor (expectativas racionales), supuesto con el cual, el individuo logra maximizar y optimizar su consumo. Este pensamiento económico postula que los individuos aprenden de sus errores, de la historia, de sus decisiones con incertidumbre y de los objetivos que persigan (Lavoie, 2014). "Como no hay necesidad de maximizar, los agentes buscan únicamente una situación con la más alta satisfacción posible" (De la Luz Tovar, 2019, p. 28).

Dadas todas estas críticas, los postkeynesianos formulan como alternativa de análisis la economía monetaria de producción, que es endogenizar al dinero. Esto implica que, como explica Chain y Narodowski:

El sistema financiero no depende de la oferta y demanda monetaria, sino de las condiciones de los intermediarios financieros, quienes son los mediadores, en las operaciones entre los distintos participantes del mercado. El dinero es como un almacén de valor y no como medio de cambio, por lo cual el dinero no es neutral (2009, p. 60). 
Con esta herramienta analítica se enfatiza la importancia del dinero en la producción, en la demanda y el empleo. El nivel de crédito y la cantidad de dinero "están ligados a la generación del ingreso, la producción y el proceso acumulativo de la economía. La creación endógena del dinero es un requisito para que el principio de la demanda efectiva se mantenga activo en la economía. Sólo esta forma de dinero (dinero-crédito) permite la generación de ingresos, crecimiento e inversión sin la necesidad de un ahorro previo" (De la Luz Tovar, 2019, p. 39).

Otro elemento importante de la escuela es el concepto del tiempo histórico, con este explican que el futuro es imprevisible pues las decisiones actuales van modificando su configuración. No aceptan las predicciones a futuro, con bases estadísticas o modelo econométricos de periodos anteriores, esto es lo que llaman la incertidumbre fundamental (Lavoie, 2014).

\section{CONCLUSIONES}

La síntesis realizada sobre reglas de cierre es muy útil para comprender la estructura económica involucrada en los modelos macroeconométricos. Introduciendo el modelo de oferta y demanda agregada, como instrumento para analizar las fluctuaciones en el equilibrio macroeconómico a corto plazo, se abstraen las interacciones y efectos de repercusión incorporados en los modelos.

La elección de las reglas de cierre es fundamental no solo para la consistencia del modelo, sino también porque en su escogencia, subyacen supuestos que sirven como instrumentos de análisis de la política económica. Estas perspectivas se desenvolvieron en los diversos pensamientos económicos que se exploraron en las secciones anteriores. De esta forma, se demostró que, como explican Taylor y Lysy (1979), diferentes especificaciones de variables endógenas y exógenas en un modelo (o suposiciones sobre cómo se cierra) cambian su comportamiento cualitativo directamente. Por tanto, un cierre keynesiano en el que la inversión es exógena, por ejemplo, y los cambios nominales en el costo primario se transfieren a incrementos de precios, demuestra una relativa insensibilidad de la distribución del ingreso funcional a los precios de los factores. Un cierre neoclásico alternativo en el que la inversión es endógena (determinada por el ahorro) y los precios de producción son fijos, es mucho más receptiva. Los modelos a gran escala están cerrados en líneas keynesianas y también tienen distribuciones funcionales relativamente insensibles.

En estas condiciones, se trata de distinguir entre gastos de inversión y los de consumo, entre inversión y especulación, a todo nivel incluyendo el financiero. No es difícil percibir que Marx y Keynes aparecen como las referencias principales para tal análisis, hoy tomadas precisamente por postmarxistas y postkeynesianos. El problema básico con los modelos no será solo una elección entre escuelas de pensamiento, si la economía está cerrada de forma neoclásica, keynesiana o de tipo Johansen; se trata también, de la disposición de la información institucional de la economía en estudio, que dará a los econometristas algunas restricciones en la elección del cierre.

La principal conclusión sobre política económica que se abstrae del compendio de modelos analizados en el documento, es que hay una disyuntiva en el corto plazo. Las políticas que estimulan el gasto aumentan la actividad económica y disminuyen el desempleo, pero también provocan un impacto sobre los precios, causando inflación, o si disminuyen los precios, se desestimula la producción. Los diferentes autores brindan una posible respuesta, pero ninguna es una solución concreta. Esto demuestra que estructurar una política económica con el objetivo de generar un mayor crecimiento o para estabilizar la economía de un país, es un accionar muy complejo y difícil, más en un sistema tan dinámico como el capitalista.

Otro aspecto importante que resalta de este recorrido de diferentes modelos y escuelas de pensamiento, es la teoría neoclásica del consumidor, los agentes son racionales, tienen unas preferencias, no importa cuáles, $y$ dadas las limitaciones que les impone el mercado y la renta de 
que disponen, actúan siempre de la mejor forma posible, sin considerar tiempo e incertidumbre, son nociones que desde siempre se han considerado relevantes a los hechos económicos. El problema es que no siempre se integran con éxito en el análisis económico.

Esta limitación ha impulsado el desarrollo de los modelos dinámicos con retardo o los modelos de endógena retardada, como soporte de teorías que toman en cuenta tiempo e incertidumbre de forma explícita. También surge la necesidad de moldear explícitamente, a los agentes que toman decisiones en esas condiciones, dando pie a los modelos de decisiones secuenciales, los cuales pretenden explicar el comportamiento observado de las variables agregadas de una economía. Sin embargo, al modelar explícitamente agentes en un contexto dinámico, se debe también evidenciar la forma en que ellos conforman sus creencias sobre ese futuro incierto, situación que impulsa nuevas discusiones $y$ formulaciones.

De esta forma, surgen las expectativas racionales: los agentes conocen o al menos pueden estimar relativamente bien las probabilidades de los sucesos futuros sin equivocarse sistemáticamente. En la práctica esto suele concretarse en el supuesto de que los agentes conocen la verdadera distribución de los fenómenos aleatorios que les afectan; o simplemente los conocen si se trata de un modelo determinista, lo que se ha venido en llamar previsión perfecta, que es la versión determinista de las expectativas racionales de Lucas (Lucas, 1983; Lucas \& Sargent 1981).

Por otra parte, al realizar el estudio desde la desagregación de un simple modelo de economía cerrada, al de una economía abierta en el corto plazo, se muestran las continuaciones, los aportes, las similitudes y las discrepancias de los diferentes autores, así como las disyuntivas de cual usar o cómo conjugar los diferentes cierres en la estructuración de modelos macroeconométricos o modelos de equilibrio general. El mantener la misma estructura matemática de ecuaciones permitió saber no solo quiénes son los autores per se, que es relativamente secundario, sino como cada autor enunció sus teorías o destacó tal o cual fenómeno empírico; se comprende cómo piensa el autor y se le brinda al lector, la posibilidad de explotar de forma más eficiente futuras lecturas de estos. Se trata de conocer al autor, porque no es suficiente con tenerlo etiquetado como perteneciente a tal o cual escuela; ningún buen economista puede ser reducido, encasillado a una escuela de pensamiento.

Lo anterior solo revive la discusión permanente del quehacer de la ciencia económica y la constante recreación de esta. Algunos pensarán que solo se realizan "refritos" de los aportes de las ideas de un grupo de grandes pensadores, pero cada día se realizan nuevos e innovadoras contribuciones, por eso realizar la sistematización anterior permite visualizar esa evolución y resaltar sus dificultades.

La síntesis realizada demuestra la persistente discusión en la dinámica macroeconómica. Las escuelas clásica y keynesiana proporcionan los elementos básicos del debate contemporáneo de la ciencia económica. En torno a ellas se han desarrollado otras, que las critican o las continúan. Si la economía fuera una ciencia puramente matemática no habría ese debate, terminaría siendo un solo modelo de pensamiento económico, pero la ciencia económica no es así, es una disciplina que se recrea constantemente, que intenta estar a la altura de los constantes cambios que sufre la sociedad actual, es una ciencia viva y en constante evolución, porque moldear política económica no es un ejercicio simple.

\section{REFERENCIAS}

Agénor, P. R. \& Montiel, P. J. (2015). Development macroeconomics (4ta ed.). Princeton University Press. https://doi.org/10.2307/j.ctvc77j6n

Anaya Díaz, A. (2014). Oligopolio y poder de mercado. Discusión de la hipótesis de precios rígidos. Economía Informa, 384, 109-127. https://doi.org/10.1016/S0185-0849(14)70413-X 
Andic, F. M. (1962). La teoría de Kaldor acerca de la distribución de los ingresos. (Sergio de la Cruz trad.). Revista de Ciencias Sociales. 6(3), 277-289. https://revistas.upr.edu/index.php/rcs/ article/view/9463

Arrow, K. J. \& Debreu, G. (1954). Existence of an equilibrium for a competitive economy. Econometrica. 22(3), 265-290. https://doi.org/10.2307/1907353

Bridel, P. (1997). Money and general equilibrium theory: from Walras to Pareto (1870-1923). Edward Elgar.

Caputo Leiva, O. (2012). La importancia de Marx para el estudio de la economía mundial actual. En J. Estrada Álvarez. (Comp). América Latina en disputa: reconfiguraciones del capitalismo y proyectos alternativos (pp. 301-324).

Castillo More, J. (2010). Análisis macroeconómico. https://www.monografias.com/trabajos-pdf4/ analisis-macroeconomico/analisis-macroeconomico.shtml

Chain L. \& Narodowski, P. (2009). Economía para empezar por el principio, una guía para aprender la economía y evaluar proyectos: la economía y sus principales escuelas: la cuestión del mercado. Aulas y Andamios. https://www.oitcinterfor.org/node/6015

De Haan, H. H. (1994). Kaleckian computable general equilibrium models: an evolutionary perspective. En R. Delorme \& K. Dopfer (Eds.), The Political Economy of Diversity: Evolutionary Perspectives on Economic Order and Disorder. Edward Elgar Publishing.

De Haan, H. H. (1998). Different perspectives in economic theory or closure rule. [Lecture notes Quantitative policy analysis, 1998 -1999. Documento inédito]. University Rotterdam.

De la Garza, E. (coord.). (1998). Ciencia económica: transformación de conceptos. Siglo XXI.

De la Luz Tovar, C. (2019). El paradigma post keynesiano: preceptos, estado del arte y visión de la economía. Revista de Economía. 36(92), 9-45. https://doi.org/10.33937/reveco.2019.114

Dewatripont, M. \& Michel, G. (1987). On closure rules, homogeneity and dynamics in applied general equilibrium models. Journal of Development Economics, 26(1), 65-76. https://doi. org/10.1016/0304-3878(87)90052-6

Dillard, D. (1981). La teoría económica de John Maynard Keynes. (9a ed.). Editorial Aguilar.

Erice Sebares, F. (2013). La teoría económica de Marx. (2a ed., vol. 3). Partido Comunista de España.

Escobar-Espinoza, A., Guevara-Castaña, D. A. \& Uribe Veloza, M. A. (2017). Modelos computacionales y análisis de la política económica en Colombia. Panorama Económico. 25(4), 535-558. http://hdl.handle.net/11227/7990

Furio Blasco, E. (2005) Los lenguajes de la Economía. https://www.eumed.net/libros-gratis/2005/ efb/index.htm

Gigliani, G. (2007, diciembre 6-7). Tasa de ganancia y macroeconomía. I Jornadas de Economía Política, Universidad Nacional de General Sarmiento. https://www.ungs.edu.ar/idei/ investigacion-idei/i-jornadas-de-economia-politica

Gujarati, D. N. \& Porter, D. C. (2010). Econometría (5a ed.). McGraw-Hill.

Hicks, J. (1989). Dinero, interés y salarios. Fondo de Cultura Económica.

Hosoe, N., Gasawa, K. \& Hashimoto, H. (2010). Macro Closure. En N. Hosoe, K. Gasawa, \& H. Hashimoto (Eds.), Textbook of Computable General Equilibrium Modelling: Programming and Simulations (pp. 122-127). Palgrave Macmillan.https://doi.org/10.1057/9780230281653_7

Jahan, S., Saber Mahmud, A. \& Papageorgiou, C. (2014). Vuelta a lo esencial ¿Qué es la economía keynesiana?. Finanzas y desarrollo. 51(3), 53-54.

Janvry, A. \& Sadoulet, E. (2016). Development Economic. Theory and practice. Routledge. https:// doi.org/10.4324/9781315715520 
Jiménez, F. (2011). Crecimiento económico: enfoques y modelos. Fondo Editorial de la Pontificia Universidad Católica del Perú.http://repositorio.pucp.edu.pe/index/handle/123456789/46611

Johansen, L. (1960). A multi-sectorial study of Economic Growth. North-Holland Publishing Company.

Kaldor, N. (1955). Alternative Theories of Distribution. The Review of Economic Studies. 23(2), 83-100. https://doi.org/10.2307/2296292

Kaldor, N. (1980). Essays on economic stability and growth: collected economic essays (Nicholas Kaldor essays). (2a ed.). Holmes \& Meier Publishers.

Kalecki, M. (1956). Teoría de la dinámica económica: ensayo sobre los movimientos cíclicos y a largo plazo de la economía capitalista. Fondo de Cultura Económica.

Kalecki, M. (1976). Economía socialista y mixta. Ensayos sobre crecimiento económico. Fondo de Cultura Económica.

Keynes, J. M. (1936). The general theory of employment, interest and money. Macmillan.

Lavoie, M. (2014). Post-Keynesian Economics: New Foundations. Edward Elgar. https://doi. org/10.4337/9781783475827

Lucas, R. E., Jr. (1983). Studies in business-cycle theory. MIT Press.

Lucas, R. E., Jr. \& Sargent, T. J. (Eds.). (1981). Rational Expectations and Econometric Practice. (vol. 1 y 2). University of Minnesota Press.

Mandel, E. (1974). La formación del pensamiento económico de Marx de 1843 a la redacción de El Capital: estudio genético. (6a ed.). Siglo XXI.

Manera, C. \& Molina, R. (2018, mayo 1). La vigente economía de Carlos Marx. Economistas Frente a la Crisis. https:/economistasfrentealacrisis.com/la-vigente-economia-de-karl-marx/

Marx, K. (1980). El Capital. (9na ed.). Siglo XXI.

Modigliani, F. (1944). Liquidity preference and the theory of interest and money. Econometrica. 12(1), 45-88. https://doi.org/10.2307/1905567

Morishima, M. (1973). Marx's economics: A dual theory of value and growth. Cambridge University Press.

Morishima, M. (1977). Walras' economics: a pure theory of capital and money. Cambridge University Press.

Nagatani, K. (1981). Macroeconomic dynamics. Cambridge University Press.

O'Ryan, R., De Miguel C. J. \& Miller, S. (2000). Ensayo sobre equilibrio general computable: teoría y aplicaciones. (Documentos de Trabajo, No 73). Centro de Economía Aplicada, Universidad de Chile. http://www.cea-uchile.cl/proyecto/ensayo-sobre-equilibrio-general-computable-teora$y$-aplicaciones-essay-on-general-computable-equilibrium-theory-and-applications/

Pérez Rodríguez, O. E. (2011). Modelo kaleckiano de crecimiento con gasto público. Revista CIFE: Lecturas de Economía Social. 13(19), 13-32. https://doi.org/10.15332/s22484914.2011.0019.01

Persson, T. \& Tabellini, G. (1999). Chapter 22 Political economics and macroeconomic policy. En J. B. Taylor \& M. Woodford (Eds.), Handbook of Macroeconomics (Vols. 1, Part C, pp. 13971482). Elsevier. https://doi.org/10.1016/S1574-0048(99)10035-1

Petit Primera, J. G. (2013). La teoría económica del desarrollo desde Keynes hasta el nuevo modelo neoclásico del crecimiento económico. Revista Venezolana de Análisis de Coyuntura. 19(1), 123-142. http://saber.ucv.ve/ojs/index.php/rev_ac/article/view/5398 
Robinson, S. (1989). Chapter 18 Multisectoral models. En H. Chenery \& T. N. Srinivasan (Eds.), Handbook of Development Economics (Vol.2, pp. 885-947). Elsevier. https://doi.org/10.1016/ S1573-4471(89)02005-X

Roca Garay, R. (2010). Macroeconomía: teorías y modelos. Pontificia Universidad Católica del Perú. https://macroeconomica.files.wordpress.com/2010/09/macroeconomia-teorias-y-modelos.pdf

Romer, D. (2006). Macroeconomía avanzada. (3a. ed.). McGraw-Hill.

Sadoulet, E. \& Janvry, A. (1995). Quantitative Development Policy Analysis. The Johns Hopkins University Press.

Sargent, T. J. (2015). Rational Expectations and Inflation. (3a. ed.). Princeton University Press. (Trabajo original publicado en 2013)

Schumpeter, J. A. (1983). Diez grandes economistas: de Marx a Keynes. Alianza Editorial.

Sen, A. K. (1963). Neo-Classical and neo-keynesian theories of distribution. Economic Record. 39(85), 53-64. https://doi.org/10.1111/j.1475-4932.1963.tb01459.x

Solow, R. M. (1956). A Contribution to the Theory of Economic Growth. Quarterly Journal of Economics. 70(1), 65-94. https://doi.org/10.2307/1884513

Solow, R. M. (1957). Technical Change and the Aggregate Production Fucntion. The Review of Economics and Statistics. 39(3), 312-320. https://doi.org/10.2307/1926047

Soto, V. G. (2008). El stock de capital industrial medido a través de la relación inversión-empleo: estimaciones para los estados mexicanos. Revista Ensayos, 27(1), 53-80. http://ensayos.uanl. mx/index.php/ensayos/article/view/105

Taylor, L. \& Lysy, F. J. (1979). Vanishing Income Redistributions: Keyneysian clues about model surprises in the short run. Journal of Development Economics, 6(1), 11-29. https://doi. org/10.1016/0304-3878(79)90033-6

Wade, J. (1833). History of the Middle and Working Classes. (3a ed.). E. Wilson.

Walras, L. (2014). Léon Walras: Elements of theoretical economics: or, the theory of social wealth. (D. A. Walker \& J. van Daal, Eds. y Trads.). Cambridge University Press. https://doi. org/10.1017/CBO9781107585676

Este artículo se encuentra disponible mediante la licencia Creative Commons Reconocimiento-NoComercial-SinObraDerivada 3.0 Costa Rica. Para mayor información escribir a revista.iice@ucr.ac.cr. 